\title{
Scaffolding Students' Independent Decoding of Unfamiliar Text with a Prototype of an eBook-feature
}

\author{
Stig T. Gissel \\ University College Lillebaelt and \\ University of Southern Denmark, Odense, Denmark \\ sttg@ucl.dk
}

\begin{abstract}
This study was undertaken to design, evaluate and refine an eBook-feature that supports students' decoding of unfamiliar text. The feature supports students' independent reading of eBooks with text-to-speech, graded support in the form of syllabification and rhyme analogy, and by dividing the word material into different categories based on the frequency and regularity of the word or its constituent parts. The eBook-feature is based on connectionist models of reading and reading acquisition and the theory of scaffolding. Students are supported in mapping between spelling and sound, in identifying the relevant spelling patterns and in generalizing, in order to strengthen their decoding skills. The prototype was evaluated with Danish students in the second grade to see how and under what circumstances students can use the feature in ways that strengthen their decoding skills and support them in reading unfamiliar text. It was found that most students could interact with the eBook-material in ways that the envisioned learning trajectory in the study predicts are beneficial in strengthening their decoding skills. The study contributes with both principles for designing digital learning material with supportive features for decoding unfamiliar text and with a concrete proposal for a design. The perspectives for making reading acquisition more differentiated and meaningful for second graders in languages with irregular spelling are discussed.
\end{abstract}

Keywords: eBooks, scaffolding, text-to-speech, literacy acquisition, decoding, connectionism, Design-Based Research

\section{Introduction}

The United States National Reading Panel (NRP) found that systematic phonics instruction is the most efficient method of reading instruction, especially in kindergarten and first grade, when compared to whole-language programmes and other programmes that do not teach phonics ex-

Material published as part of this publication, either on-line or in print, is copyrighted by the Informing Science Institute. Permission to make digital or paper copy of part or all of these works for personal or classroom use is granted without fee provided that the copies are not made or distributed for profit or commercial advantage AND that copies 1) bear this notice in full and 2) give the full citation on the first page. It is permissible to abstract these works so long as credit is given. To copy in all other cases or to republish or to post on a server or to redistribute to lists requires specific permission and payment of a fee. Contact Publisher@InformingScience.org to request redistribution permission. plicitly and systematically (National Reading Panel [NRP], 2000). In typical phonics-based learning materials, students are taught a limited number of letter-sound relations and read texts with highly controlled vocabulary to practise using the alphabetic system. These learning materials leave little or no room for teacher discretion in differentiating phonics instruction (NRP, 2000). Nevertheless, the acquired skills 
of decoding words through systematic phonics instruction have a significant impact on comprehension for younger students. However, the effect on comprehension of beginning the phonics instruction above first grade diminishes beyond significance $(\underline{\mathrm{d}}=0.12)$, except for the disabled readers $(\underline{d}=0.32)$, who benefit significantly in second grade (NRP, 2000). It would seem that second grade is a turning point for the efficiency of systematic phonics instruction. In the NRP report, it is suggested that further research address the question of if and how phonics instruction should continue in second grade and beyond, a topic not covered in the NRP report, and the important issue of determining how comprehension work can be combined with decoding instruction. This paper addresses these challenges.

The aim of this study is to develop a digital feature that strengthens students' decoding skills while reading the same, unfamiliar text for meaning. This paper presents the results of an intervention involving Danish second graders using a newly designed prototype of an eBook material. I am trying to develop a digital mechanism for supporting and teaching students decoding on single-word level when working with unfamiliar text.

In the present study, focus is on the supportive potential of eBook features. The eBook texts in the study were presented on laptop computers and did not contain moving images or interactive activities apart from the supportive features (Zucker, Moody, \& McKenna, 2009). Using eBooks with digital support has the potential to strengthen student comprehension of text and reading engagement. However, it is less obvious that using eBooks for educational purposes can strengthen students' decoding skills. In a review, assessing the effect on decoding from using eBooks no significant effect was found (Zucker et al., 2009).

Of course, decoding is not an end in itself. Comprehension is the ultimate aim. The problem is finding a way to teach students to decode while reading for meaning, and this challenge extends beyond eBooks (Gough, 1981). LaBerge and Samuels (1974) pointed out that if decoding is not performed automatically, it drains the reader's limited attention because humans are singlechannel processors. Therefore, the rather isolated practising of decoding skills using texts with controlled vocabulary has been used as a first step in reading instruction, without much attention given to comprehension. Another widely used way of practising decoding skills is by making students work with familiar text, for example, text previously read aloud by the teacher - in which case students are not decoding for meaning.

In the present study text-to-speech (TTS), i.e., technology that allows text to be read aloud by a computer-synthesized voice, was used as part of an eBook-design including other supportive features. The intervention included a specific design for learning guiding student interaction with the eBook, which sets it apart from other studies with talking books or TTS (Lefever-Davis \& Pearman, 2005; Parr, 2008). Both the design of the eBook and the design for learning reflect a theory-based attempt to maximize the effect of the support on strengthening student decoding skills. Using Design-Based Research (DBR) as methodological approach to iteratively develop, evaluate, and refine the design in a real classroom context, I observed students' interaction with the eBook-design and made changes to the design in order to fine-tune the scaffolding that TTS and other features could provide for students with different needs. Instead of testing TTS and other supports for effect and explaining away a possible lack of effect with unwanted student behaviour, I changed the design in an attempt to make student behaviour as beneficial as possible for strengthening decoding skills.

This paper reports on a design experiment, which is a different kind of experiment than experimental or quasi-experimental research. In a design experiment, the goal is to improve an envisioned learning trajectory and the designed means of supporting the envisioned learning (Cobb \& Gravemeijer, 2008). The goal is not to determine that the envisioned learning trajectory works. It is a formative evaluation. Like other explorative design experiments, this study was challenged 
by the complexity of real-world contexts. Large amounts of both qualitative and quantitative data were produced from testing different designs in an iterative design process (Collins, Joseph, \& Bielaczyc, 2004). The researcher will have to make selective interpretations in the process of the experiment to support student learning (Cobb \& Gravemeijer, 2008). Retrospectively, the researcher can place the results of the experiment in a relevant theoretical context, which this paper aims to do.

From state-of-the-art reading research the two approaches to use computers to simulate visual word recognition, the Parallel Distributed Processing Model (the connectionist approach) and the Dual-Route Cascaded Model (Tracy \& Morrow, 2006) seem to have roughly equal explanatory power (Lupker, 2005). However, the connectionist approach is a potential game changer in terms of the way I envision the practical implications of the theory. It is only a potential game changer because connectionist researchers have put effort into developing the theoretical base for understanding reading and not as much effort into putting the theories to practical use to solve educational problems (Shultz, 2010). I stress my own interpretative role in putting the theory to practical use. What the practical implications of connectionist theory should be are by no means obvious. The theory builds upon assumptions based on the findings of computer simulations. However, the learning conditions of the student will differ significantly from those in the simulations (Seidenberg, 2007). Designing learning material based on theories of reading and reading acquisition requires interpretation and recontextualisation of the theory in order to put it into practice (Gissel, 2015).

\section{Literature Review}

Previous research studied students' use and the effect of using the eBook-features TTS and subword level support and hints. Results indicate that an efficient transformation (Puentedura, 2006) of reading instruction concerning decoding using these features is yet to come. In the present study connectionism is the theoretic base that determines how and why students might benefit from using these features. Theory of scaffolding is brought in to offset some of the drawbacks from giving students access to TTS and to enhance the effect of using TTS on decoding skills.

\section{The Promise of Text-To-Speech Technology}

The TTS feature typically found in eBooks has been tested for effect on decoding. Most studies have investigated TTS as a tool for remedial reading (Karemaker, Pitchford, \& O'Malley, 2010a; Olofsson, 1992; Olson \& Wise, 1992; Zucker et al., 2009). Research suggests that stronger readers gain less from using TTS, and the conclusion has often been that only struggling readers should be offered TTS (Balajthy, 2005). Focusing on computer-mediated remediation, Olson and Wise (1992) showed a significant gain for students in grades 2-6 who could request whole-word feedback on difficult words (see also McKenna, Reinking, \& Bradley, 2003); they also found a significant gain for students receiving segmented feedback (onsets, rimes or syllables).

In the present study, TTS and other types of support for decoding are considered a potentially relevant aid to all students in their literacy development. The point of TTS is that if a student cannot go from orthographic input to meaning or map from orthography to phonology and then to meaning, text-to-speech allows him to access the meaning of a word using his knowledge of spoken language. If the student has attempted to decode the orthographic material, TTS can map between orthography and phonology, and the student can then revise his initial hypothesis regarding pronunciation of the word parts. In connectionist terms, the students can calibrate the connections between units and their weight. However, following the logic of connectionism - if the student does not attempt to decode the orthographic material it will zero the effect on decoding skills. 
Previous research suggests that TTS can have a positive impact on decoding for normally developing readers. Karemaker, Pitchford, and O'Malley (2010b) found significantly greater gains in normally developing 5-6-year-old readers' word recognition and word naming from using wholeword multimedia software that reads a story aloud and highlights each word than from using typical whole-class teaching methods. Reitsma (1988) compared guided reading with sustaining feedback, independent reading with whole-word TTS and reading-while-listening and found that both guided reading and TTS reading were significantly more effective than both the control condition and reading-while-listening with first-grade students. Surprisingly, the guided reading and independent reading with whole-word TTS were equally effective. Reitsma suggests that strict control of reading accuracy is not an essential prerequisite for improving reading skills.

\section{Connectionist Theory of Word Reading}

Connectionist theory of word reading and reading acquisition provides the theoretical base for redefining how phonics instruction should take place in second grade. I will explain what phonics instruction entails in this view and how it can be structured. Furthermore, the connectionist view of the instructional task allows for individualization of the learning process through digital scaffolding, thereby balancing differentiation and the need for phonics instruction. But for now I will present the theory in general.

Connectionist models of reading acquisition assume that we learn to decode through exposure to words and text. When encountering an orthographic input, we use a finite set of units representing the spellings (orthography) and pronunciations (phonology) of words (Seidenberg, 2005). The representations are distributed; they represent a large set of spelling/sound patterns. All cognitive information is stored as a series of connections between units. Each possible pronunciation has a weight depending on the frequency of previous exposure, and all the possibilities connected to the spelling pattern are activated when the reader encounters the spelling pattern. The connections between units grow stronger or weaker with exposure to print.

According to connectionist models of reading, we use the same mechanism for processing words regardless of the degree of consistency between spelling and sound. English and Danish orthographies are not rule-governed; they are in fact quasi-regular (Seidenberg, 2005). In a deep orthography like Danish or English there are regularities, but the regularities are found at different grain sizes. Some letters have a standard pronunciation when found, for example, at the beginning of a word but not always in other positions. Rimes are regularities, but these regularities are mixed with more atypical phonetic phenomena that also have to be encoded by the reader (Seidenberg, 2007; Ziegler \& Goswami, 2005).

Connectionist models explain how students learn to read in deep orthographies without learning phonics rules and rote learning of all irregular words. This is directly opposed to standard dualmechanism theories, which assume that we have two types of knowledge and different mechanisms for processing two types of words, regular words and exceptions. A regular word in which every letter represents its most common sound is processed through the nonlexical route. Here, rules can be used to decode the word. Readers use links between graphemes and phonemes to pronounce words, not larger units (Treiman, Mullennix, Bijeljac-Babic, \& Richmond-Welty, 1995). The exceptions are handled through the lexical route. In the lexical route, we have memorized spellings and pronunciations of irregular words (Coltheart, 2005).

The practical consequences of connectionist theory could be a more quasi-regular, principlebased approach to reading instruction than what dual-mechanism theories would prescribe. Students do not have to be taught a lot of 'rules' and practice applying them. Instead, students should be exposed to print materials as often as possible. According to this model, students learn to read 
by reading. They must process spelling patterns and combinations of letters and compare this to how words really should be pronounced.

From a connectionist perspective, it is important that students continue trying to decode words independently before getting support from TTS. Access to TTS could minimize the risk of frustrating students by making them read texts that are too difficult, i.e., when the child is unable to pronounce $10 \%$ or more of the running text (Betts, 1957). Furthermore, if the range of matching text difficulty level can be widened for the individual student the whole class could be able to read the same texts allowing for teacher and peer feedback, classroom discussions, vocabulary teaching, and comprehension work. The eBook could be the way to make sustained silent reading a more efficient way of improving reading achievement than the NRP-report suggests (NRP, 2000).

\section{Student Use of TTS}

Previous research on student use of TTS has indicated that students find it difficult to selfregulate, i.e., monitor their understanding and select effective reading strategies, sufficiently when using TTS. Furthermore, there is reason to assume an important difference between students using TTS and other scaffolding functions that they have to pull from the learning material in a real classroom situation and in a controlled environment. Classroom-based research with multimedia literacy software is rare (Karemaker et al., 2010b). A very important point in studying student behavior is that the presence of the researcher observing the child reading might alter the behavior significantly.

Lefever-Davis and Pearman (2005) observed first grade students using CD-ROM storybooks with optional TTS for selected words, sentences, or the whole story. They found that some students relied too much on the TTS function and often did not try to decode words independently. Furthermore, the students often clicked on words that had previously been read aloud, or they had words that they were able to decode independently on a previous occurrence read aloud at a later instance. Some students, on the other hand, used TTS as a model to strengthen their ability to read aloud or chimed along with the computer narration. Other students used the TTS to confirm that they had decoded a word correctly.

The findings of Lefever-Davis and Pearman (2005) tell us about children's informal interaction with multimodal texts but less about the potential of these materials in reading instruction. The researchers did not cue the students on how to use the storybooks, instead intervening as little as possible during the reading sessions. If the storybooks were not part of a design for learning, it is not surprising that the students did not bother to try decoding. Littleton, Wood, \& Chera (2006) found that boys 5-6 years of age used the features in a talking book adaptively and appropriately according to their phonological proficiency.

In a previous study (Gissel, 2014), I analyzed student behavior (age 7-8) when students interacted with a talking book with both TTS for single words and whole pages. In the study, the students were instructed to try to decode every word independently before activating TTS. As in the present study, the texts used were unfamiliar and would be considered at frustration level for most students without the support. I found that only 4 of 15 students in the class tried to decode independently but that these students underused the support or did not use it at all. These were the only students who could be assumed to benefit from the activity. Other students overused the support and were not trying to read independently or they were guessing or activating TTS too quickly. Then there were the students for whom decoding the text was outside their zone of proximal development. The study indicated a need to limit the scaffolding that TTS provides for students who overuse the support. Therefore, in the present prototype, TTS is only available for 
some words. My previous study also revealed the need to make relatively skilled readers use the support when they needed it.

\section{Sub-Word Level Support and Hints}

Lewin (1998) carried out a survey in which teachers were asked which features they would like to find in future eBooks. It was found that teachers would like decoding support beyond whole word pronunciations. Teachers indicated whether they considered feedback at the level of onset/rime or syllable an improvement to their eBook software. Furthermore, they could choose to have the software prompting students to decode a word independently by providing a hint. More than $60 \%$ chose the hint-function, onset \& rime came in second with less than $60 \%$, and about $20 \%$ saw syllabification as a valuable addition to the software. In addition, teachers requested features to individualize instruction. Strangely, despite teachers' wishes, research attempting to design eBooks and learning materials using TTS functions in combination with scaffolding features to support decoding such as hints and feedback at sub-word level has been very scarce in the last decade.

McKenna et al. (2003) concluded that their attempt to contextualize phonics instruction by providing supportive features in talking books was ineffective on decoding measures. It was found that students either over- or underused the support. Of relevance to the present study is also the observation that a feature in the software providing phonics analogies (saying "hat like cat") was too intrusive for the students; students were distracted and unable to follow the story (McKenna et al., 2003). Chera and Wood (2003) found significant improvements in 4-6 year olds' phonological awareness but no significant benefit for word reading from reading eBooks with whole page, whole word, and onset/rime highlight and pronunciation.

Lewin (2000) compared the effect of using two versions of talking book software. In one version, students could access word pronunciations through TTS. In the other, Lewin added segmented, sub-syllabic word pronunciations at the level of onset and rime, general hints to encourage independent word identification and activities to reinforce specific reading skills. The two versions were tested in an authentic classroom setting with students aged 5-6 $(n=32)$ for 15 minutes a day for four weeks. Students were paired and randomly assigned to either of two groups using different versions of the software. Lewin found no overall statistical significant difference in gains between the two groups on word reading and sentence reading.

\section{Computer-Mediated Scaffolding}

In this study, the metaphor of scaffolding is used to denote a broader range of interaction than Lev Vygotsky's (1978) language based support from the mediation through social interaction between a more capable other and the learner. Scaffolding in this study is defined as interactions between a student and other people or artifacts that support the student and enable him to perform tasks that he would not otherwise be able to perform without the scaffold. The theories of computer-mediated and analogue scaffolding and the scaffolding of reading instruction provide an overall view of the challenges any attempt at scaffolding a learning process should meet, the specific characteristics of scaffolding reading, and point to scaffolding functions that can keep students on track in trying to decode words. The theories also indicate how to use TTS optimally and strengthen decoding skills.

Caroline Liberg, a whole-language researcher, takes an ethnographic approach when studying children's authentic interactions with adults. Liberg distinguishes between effective reading and grammatical reading. Effective reading is when language is used to create and maintain meaning and the text operates effectively (Liberg, 1990). A child uses grammatical reading when effective reading is not possible; then the reader uses the principles of the alphabetic writing system to 
manipulate or operate a language object. The one-on-one interactions between adults and children are characterized by embedding code-based instruction in a meaningful context, and the child always launches the interactions. One of the instructional implications of these observations is that the grammatical perspective should not be an aim in itself in education but an aid to effective reading and should act as a mediator and a support in teaching and learning to read effectively (Liberg, 1990).

In their seminal article, Wood, Bruner, and Ross (1976) point to two key elements of scaffolding. First, the teacher must have a theory of the task and its components as well as have a clear notion as to what successful completion of the task entails. In my prototype, the connectionist theory of reading provides this theoretical base. The other requirement for scaffolding poses a serious challenge to digital scaffolding and scaffolding larger groups of students. The teacher must adapt his support carefully to students' needs based on an ongoing assessment of students' performance and understanding. The prototype evaluated in this study is a hard scaffold, meaning that it does represent a theory of the task but does not react to the performance characteristics of the individual student (Brush \& Saye, 2002). This puts pressure on the theory of the task because students' needs have to be anticipated in advance (Brush \& Saye, 2002; Sharma \& Hannafin, 2007).

Lumpe and Butler (2002) suggest that scaffolding software can act as a crutch allowing students to reach a cognitive level they could not reach on their own; the scaffolds, however, are not the software features but the interactions that take place between the software and the individual student (Lumpe \& Butler, 2002). Whether student interaction with a digital scaffold is beneficial depends on how students use the learning material. For example, do they use the supportive features that tap into their zone of proximal development appropriately?

The assumption that students will independently access the support that is relevant to them cannot be expected to apply to all students (Anderson-Inman \& Horney, 2007). Students often over- or underuse support that has to be pulled by the student, which the aforementioned literature on student use of TTS exemplifies, and the students that need support the most are the least strategic users (Anderson-Inman, Horney, Chen, \& Lewin, 1994; Gissel, 2014; McKenna, 1998). Furthermore, it seems that students find it difficult to assess how challenging the task of reading a particular word is. Van Daal and Reitsma (1993) investigated whether or not normal readers differentiate more between difficult and easy words than disabled readers. They compared the results of a reading task with an arithmetic task to determine if students are less sensitive to task difficulty when reading than is the case in other types of task. They found that both normal and disabled readers were far less sensitive to word difficulty than to sum difficulty in the arithmetic tasks. In addition, the disabled readers kept on using the TTS support instead of decoding the words independently.

To sum up, the effect of using TTS and sub word level support for strengthening word recognition in actual classrooms has not been clearly established nor exploited. I suggest that we explore how students actually interact with a design that incorporates TTS and sub word support while countering student overuse of TTS. The design experiment aims to make ongoing improvements to the design thereby improving its support of the envisioned, theory based learning trajectory.

\section{DBR and Realist Evaluation}

The research design in this study is based on DBR and realist evaluation. DBR is a genre of research that allows the scientist to address educational challenges and vacuums. In educational design research, the iterative development of solutions to practical and often complex educational problems requires that research is rooted firmly in real-world contexts to make it likely that both theory and practical solutions can make a difference in actual classrooms (McKenney \& Reeves, 2012), thus having high ecological validity (Bryman, 2012). A defining characteristic of DBR is 
that the design is rooted firmly in theory. The researcher must have a theoretically and evidencebased basis for assuming that the design intervention will work and for envisioning how it will work (Majgaard, Misfeldt, \& Nielsen, 2011). Furthermore, DBR aims to produce theory on learning and teaching (Barab \& Squire, 2004).

In realistic evaluation, like DBR, the starting point is the programme theory, which is a valid perception of how and why an intervention is supposed to work. The programme theory is composed of concrete mechanisms, which are the underlying processes that make the intervention produce the desired outcome.

Pawson and Tilley (2004) point out that the outcome of an active programme depends on the active engagement of the individuals who are supposed to benefit from the intervention. Furthermore, programmes are always embedded in particular contexts, which may or may not support the programme theory.

\section{Methodology}

My design intervention aims to solve practical challenges in reading instruction by developing an eBook-material in collaboration with teachers. The prototype is evaluated and refined through cycles of formative evaluation (Nieveen \& Folmer, 2013) with Danish second grade students. The formative evaluation of the intervention with the learning material was carried out as a realistic evaluation (Pawson \& Tilley, 1997).

The intervention theory in this study is multifold; the designed learning material and its design for learning reflect many elements and decisions and is in itself an interpretation and/or recontextualisation of the underlying theories.

Realistic evaluation, like DBR, is highly sensitive to context; an outcome is in this view produced by particular mechanisms acting in particular contexts (Figure 1). In the present study, I am observing how individual students interact with the learning material to see if it matches the students' dispositions and needs with reference to strengthening decoding skills and whether using the material triggers mechanisms that can be beneficial to the students.

When analyzing students using the learning material, I am looking for outcome patterns. I am not testing students' gain in decoding skills but am rather looking for individual behavioral patterns that may or may not be beneficial in strengthening decoding skills according to the programme theory and intended and unintended outcomes of the intervention. The point of the formative evaluation is to determine why some students do not behave as intended and to try to redesign the programme to make more students interact optimally with the learning material.

To illustrate why a design experiment could contribute to research on student use of TTS and supportive features in ways that experimental research cannot I will use the research of Lewin (2000) as an example of the experimental approach. When Lewin, as mentioned in the literature review, compared two versions of talking book software she found no overall significant difference in gains between groups. From the logging feature in the software it was evident that students using the Basic version of the software requested significantly more word pronunciations than students of the same ability levels using the Enhanced version. These are important findings, but as with similar approaches (Chera \& Wood, 2003; McKenna et al., 2003), Lewin can only guess as to why these behavioral patterns occur. The data do not show whether or not students using the Enhanced software actually read the words or if they did not bother listening to the segmented feedback. Furthermore, the research process ends with the testing of the hypothesis. There is no attempt at redesign to make the software more efficient. 


\section{Generative mechanisms}

Connectionist theory of how we acquire orthographic representations.

Theory of scaffolding.

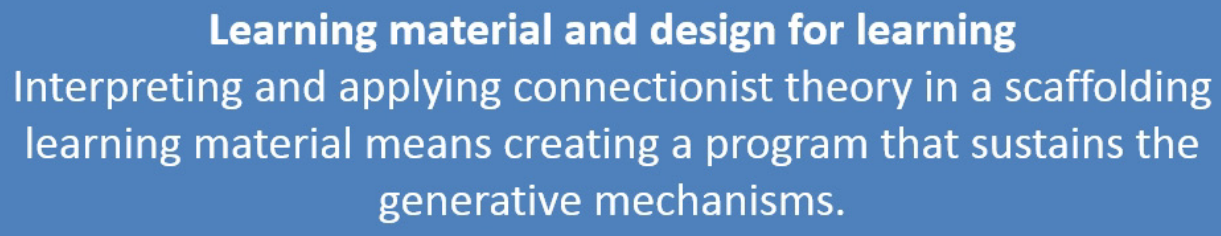

Learning material and design for learning

Interpreting and applying connectionist theory in a scaffolding

learning material means creating a program that sustains the generative mechanisms.

Reading in context

The student with individual preferences and

dispositions acts in a particular context and

interacts with the program (the eBook and

design for learning).

Figure 1. Based on theory, I deduce the generative mechanisms. These are in turn transformed into an eBook-design that is used by students with different dispositions and needs for reading.

In the following sections, the programme theory (Pawson \& Tilley, 1997) of the learning material is made explicit. In other words, I will describe the theoretical base for the elaborated mechanisms that constitute the process that is meant to lead to strengthened decoding skills. The programme theory is substantiated using underlying theories and research of reading, reading acquisition and (digital) scaffolding. The design of the learning material is described along with the findings and reiterations of the learning material in the stages of formative evaluation through interventions in a second-grade classroom.

\section{Extrapolating Principles of Design from Connectionist Theory}

How could a learning material that is based on the connectionist theory of reading acquisition be designed? The answer, of course, is that it could be done in numerous ways. However, in the following, I will establish four principles for learning material and design for learning with the aim of supporting students' decoding skills and literacy acquisition that can be extrapolated from connectionist theory. 


\section{Principle \#1: Support for Mapping between Orthography and Phonology}

Students have to practice and to be supported in mapping between orthography and phonology. The eBook feature should make the student focus on the spelling of each word and make the student try to decode it using the orthographic material. If the student is not successful in decoding the word independently or is unsure he identified the correct word, he should be supplied with the target to help him establish the relevant connections between orthography and phonology. Connectionist simulation models indicate that the correspondence between sub-word letter patterns and phonology can be implicitly learned from whole-word feedback (Seidenberg \& McClelland, 1989).

Share $(1995,1999)$ found that students could acquire lasting orthographic knowledge of single words by individually working on the phonological recoding of unfamiliar words. Every successful decoding of a new word potentially gives the student a word-specific orthographic representation of the word. Share (2004) showed that even a single exposure can be enough, and Bowey and Muller (2005) showed that self-teaching also applies to silent reading. Share's experiments were carried out with texts written in Hebrew, which is a shallow orthography, but Cunningham, Perry, Stanovich, and Share (2002) showed that there is a similar effect in deep orthographies.

Rosenthal and Ehri (Ehri, 2005) found that it is not essential that students sound out the words in the process of decoding them. What is essential for forming orthographic representations is the implicit, spontaneous activation of alphabetic knowledge and connecting orthography to phonology (Ehri, 2005). Connectionist theory also stresses the processing of the orthographic input as essential to the development of word reading skills and knowledge of spelling patterns (Adams, 1990).

\section{Principle \#2: Exposure to Relevant Orthographic Patterns}

The eBook feature should not teach students phonics rules or make them use certain reading strategies that they have to apply deductively. Instead, students need to be continuously exposed to the relevant orthographic patterns. Therefore, the learning material should support the students' reading process, enabling them to keep reading without being frustrated or distracted from focusing on the orthographic input and trying to decode it. According to connectionist theory, students must grasp the component parts of the words instantly. The stimulations of the visual recognition units have to be active at the same time for the crucial connections between the letters to be learned by the student (Adams, 1990).

When a student is able to correctly and independently decode a word, he needs no further codebased instruction relating to the word or its constituent parts. Decoding the word will provide the exposure necessary to strengthen connections between units.

\section{Principle \#3: Support for Identifying the Most Relevant Units in a Word}

Because the regularities are found at different grain sizes, support must pertain to and help students identify the most relevant units in every word. In the case of rimes, for example, these units show much more regularity than we find at the level of individual graphemes and phonemes (Treiman et al., 1995). In the dual-mechanism approach, Danish words containing rimes will often be considered irregular because the vowel is pronounced irregularly or a letter is silent; if these words are to be learned by rote as noncomponential representations, the students fail to become aware of the unit that allows for maximum generalization (Harm, McCandliss, \& Seidenberg, 2003). 
The flexible unit-size hypothesis (Brown \& Deavers, 1999) describes children as flexible and adaptive in terms of which levels of spelling-sound correspondence they use for reading. Instructional design, task requirements, and support influence which units students use for decoding. Scaffolding students' reading acquisition with controlled vocabulary with highly regular links between phonemes and graphemes will make students use these small units for decoding. However, if regularities in Danish and English are found at different grain sizes, students should be taught to identify these different units. Intervention research using TTS combined with the highlighting of different orthographic segments (whole word, syllable, sub-syllable, and letter) did not show a clear advantage of any one unit size (Olson and Wise, 1992; Wise et al., 1989). Levy and Lysynchuk (1997) had similar results using index cards. In the present intervention, I am working from the assumption that the characteristics of the individual word should determine which units are the most relevant for the students to use.

Students should be supported in identifying the relevant orthographic patterns to obtain optimal conditions for generalizing from the current incidence to other incidences. Skilled readers differ from poor readers in their knowledge about sub-word spelling patterns (Adams, 1990). Becoming a skilled reader means being able to quickly identify and process the relevant units.

Pointing students towards the relevant units could be all the support they need to read unknown words. At the same time, students using this support will strengthen decoding skills each time they successfully read a word and its constituent units. This is an important point in relation to scaffolding reading acquisition. Connectionism provides a theoretical base for assuming that directing a student's attention to the relevant units is sufficient instructional feedback for strengthening decoding skills for the word he is trying to decode while at the same time cueing the student, helping him to move forward in his reading process.

This echoes the findings of Cole (2006), who videotaped first-grade teachers to find out what teachers say and do when they scaffold novice and fluent students. She also tried to determine which kinds of support were most helpful for the students trying to decode and comprehend texts in her qualitative study. Cole concluded that decoding cues that were directly related to the graphophonics (Goodman, Watson, \& Burke, 2005), i.e., the orthography and phonology of the text, supported fluency. She labelled this kind of support primary cues; primary cues have a direct effect on decoding and help students move forward (Cole, 2006). Examples are when the teacher utters a sound or part of a word and when the teacher masks part of the word. Secondary cues, on the other hand, pull students away from the text by making them consider phonics rules (that are often quite complicated and do not always apply and hence are not rules) or to consider whether a sound is short or long.

\section{Principle \#4. Students Should Have Deep Exposure to Frequently Occurring Units}

Some units occur more frequently than others. The more frequent a spelling pattern is, for example, the more important it is that students automate decoding of the unit. According to connectionist theory, a normally developing reader will soon read the most frequent orthographic patterns effortlessly. Students who have not yet automated decoding of the most frequent patterns and words should be thoroughly exposed to these patterns in order to automate the decoding. I will call this process of thorough exposure 'deep exposure'.

For these mechanisms to occur, students have to self-regulate and stay motivated. To make students use the support, that is, the opportunity to be provided with a target (principle \#1) or get support in the process of decoding a word (principle \#3), they have to self-regulate. This is a key challenge in my project. Students have to react if a word does not make sense in and of itself or in the context. In other words, the process of decoding must be interrelated with comprehension. 
This is where it becomes essential that students are working with the same text so they can get feedback on their comprehension. In addition, the text will have to be interesting to facilitate recruitment (Wood et al., 1976), make students keep reading, and use the support (Gissel, 2015).

\section{The eBook-Features}

In describing how the prototype of the eBook is intended to support decoding and teach decoding skills, I will use Wood et al.'s (1976) scaffolding functions and refer to the principles extrapolated from the connectionist theory and research of reading that was introduced in the previous sections. When describing the material, I will also describe how the student is meant to act when using it. These behavioral patterns will be used later to determine outcome patterns for individual students and the evaluation of the programme theory.

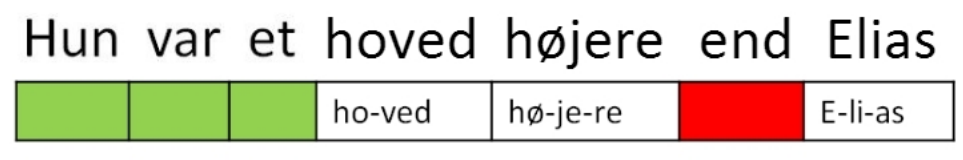

\section{og havde opstoppertud.}
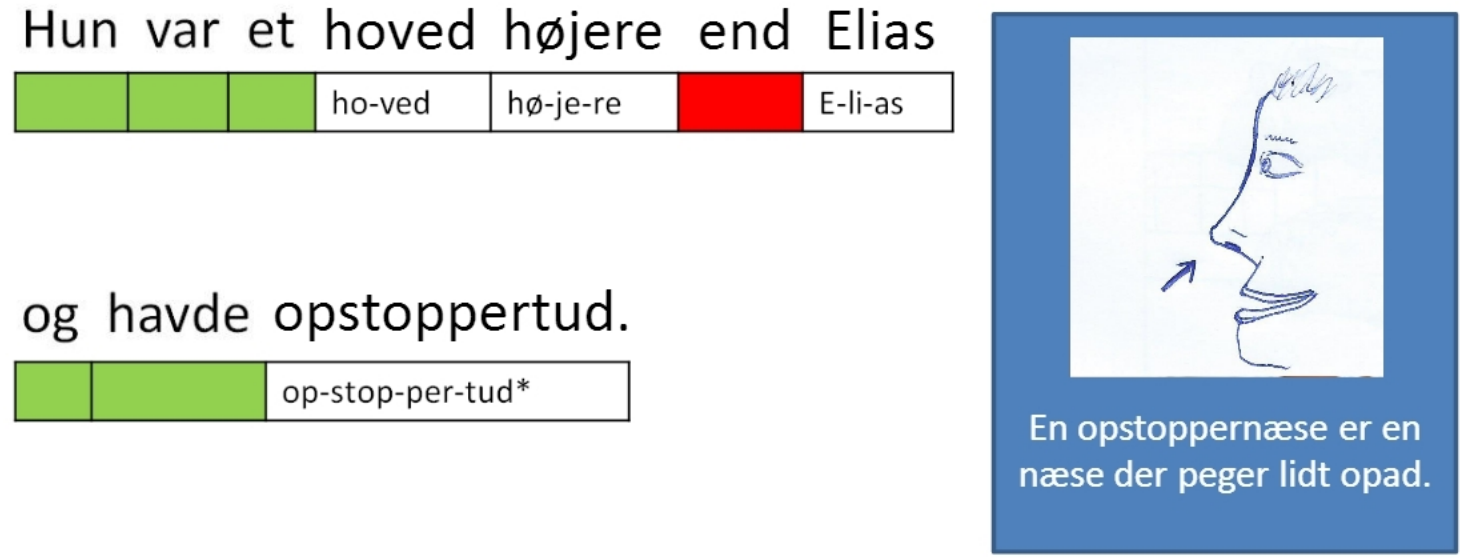

"Ja, det er så Elias," sagde Far til hende.

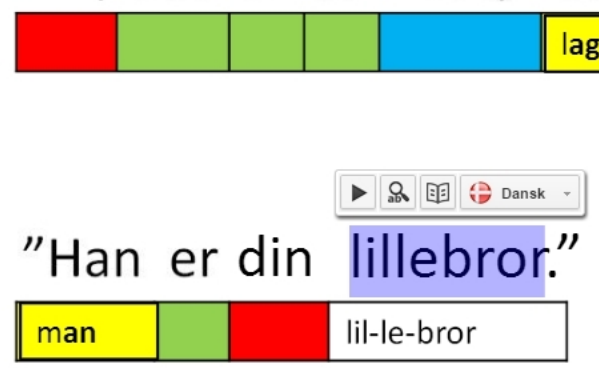

Figure 2. The prototype of the eBook for second grade. The word "lillebror" is highlighted by the user and by pressing play it is read aloud. The text says 'She was taller than Elias by a head and was snub-nosed. "Yes, this is then Elias," Dad said to her. He is your little brother.' The blue box says: 'A snub-nose is a nose that points upwards.'

When using the learning material (Figure 2), the student reads until he needs help (principle \#2). When the student encounters a word he cannot read independently, he has to look below the line of text to see what category of word he is trying to read. This in turn tells him what he must do to decode it and strengthen the decoding skills relevant for the word in question and which kind of support is available. In Caroline Liberg's terms (1990), the student reads effectively until this is no longer possible; then the student either switches to grammatical reading or is simply given the correct word.

The aim to balance decoding for meaning and the students' learning to map between orthography and phonology will primarily be obtained through the students' use of TTS technology. For this 
balance to occur students are required to limit and postpone their use of TTS; students have to try to process the orthographic material before activating TTS (principle \#1).

TTS allows the student to access the semantics component directly using his knowledge of the spoken language, thereby understanding the word independently of his reading skills. This serves to reduce student frustration (Wood et al., 1976). If the student has tried to decode a word using the orthographic input, he can map between the orthographic and phonological codes, which are highly correlated (Seidenberg, 2007) (principle \#1). Thus, the student can revise his initial hypothesis regarding the pronunciation of the word parts. This process resembles backpropagation, a learning process used in connectionist simulations of reading processes (Seidenberg, 2007).

As mentioned, student underuse of the support is likely to occur. This aim is not covered in the present intervention, but I assume that when the class gets used to working with the same text, students will become aware that it matters whether or not what they are reading is making sense. The collective comprehension work will act as direction maintenance (Wood et al., 1976). In addition, underuse of the support by relatively skilled readers is less of a problem compared to overuse. It is more important that students keep trying to decode the words instantly and less important that they are provided with the correct target on every trial; representations that allow generalization are more valuable than word-specific knowledge (Seidenberg, 2007) (principle \#3). Most importantly, my previous study (Gissel, 2014) revealed the need to support the struggling readers in handling the complex task of reading an unknown text and making sure that they would benefit from the activity.

An essential part of the design is the marking of critical features (Wood et al., 1976) and helping the students to discriminate between relatively hard/easy words and important/less important units. Using color codes, the learning material divides words into different categories based on the frequency and regularity of the word or its constituent parts (Figure 3). Connectionism also provides the basis for this part of the theory of the task. Some words and parts of words are marked as extremely important to master because of their frequency (principle \#4). Other words are either marked as being quite difficult (being multisyllabic, consisting of infrequent word parts and/or having irregular neighbors). Reduction in degrees of freedom (Wood et al., 1976) is adapted to the difficulty level and the relative importance in relation to strengthening decoding skills for every word in the text. Therefore, students are instructed to use TTS without further ado for the most difficult or infrequent words/word parts whereas the students' use of TTS is delayed through decreased usability for the most frequent words. This also serves as direction maintenance and frustration control (Wood et al., 1976). The student is challenged to read the words assumed to be within his zone of proximal development independently without using TTS, but he also has an indication that some words are quite difficult and that he should not be frustrated that he is not able to decode them independently.

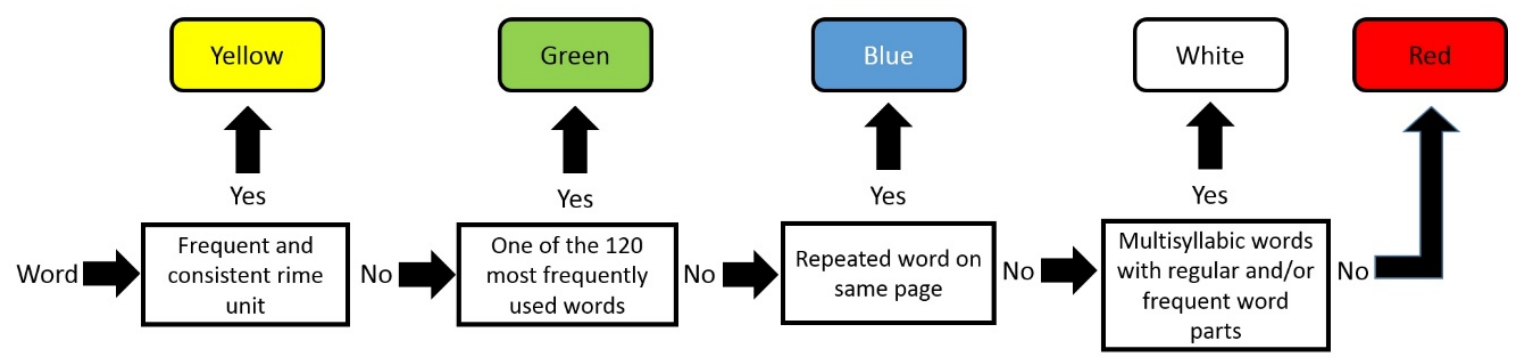

Figure 3. Procedure for categorizing words in the instructional texts. Each word is placed into one of five categories according to a procedure extrapolated from connectionist theory. 
Studies suggest that children identify onset rimes more easily and earlier than phonemes (Ziegler \& Goswami, 2005). The words with a yellow box are words from onset rime families. The student cannot have the target word read aloud using TTS. Instead, the student gets a cue through a written keyword that rhymes with the target word; the student will have to transfer the rhyme from the analogous word to the target. The student can have the cue word read aloud with TTS, if he cannot decode it independently. By using rime analogy and substitution of one or two consonants, the student decodes the target word and gets three exposures to the rhyme, which I will term deep exposure (principle \#4). This gradual support is expected to be less intrusive than the support discussed in McKenna (1998).

Words in the green category cannot be read aloud immediately by TTS. This category consists of 86 of the 120 most frequently used words in the Danish language (34 of the 120 most frequent words consist of rimes and are therefore placed in the yellow category). The 86 words are for the most part short but highly irregular. For these words that are not in high correlation to the phonological code a direct path between orthography and semantics has to gain influence from thorough student exposure to the same words (Seidenberg, 2007) (principle \#3). The student in the intervention is expected to either be able to read them independently or to make an effort to learn to read them. Here, I rely on and try to strengthen the frequency effect (Lupker, 2005). If the student cannot read the word independently, he has to remember how it is spelled and access the word in another document, where they can be read aloud with TTS. That gives the student at least two exposures to the word and a mapping to phonology. This is deep exposure (principle \#4). From a scaffolding point of view, the combination of the inconvenience of obtaining the correct pronunciation and the student's awareness of the frequency of the word should encourage him to learn to read the word independently, acting as direction maintenance (Wood et al., 1976). Whenever these words contain a frequent pattern, this pattern is highlighted (principle \#3); for example, the silent $h$ in the Danish words beginning with hv.

It is only the first occurrence of a word on a page that can be read aloud using TTS. On the second occurrence, the blue colored box signifies that the student either has already read the word independently or has attempted to read it on a previous occasion, perhaps using the graded support and/or TTS. This helps the student maintain direction (Wood et al., 1976) toward the ultimate goal - to learn to read the words and word parts independently, without the scaffold, and counters overuse of the scaffold.

Multisyllabic words that do not fall into one of the other categories and that consist of regular and/or frequent word parts are divided into syllables or morphemes. Thus, the student can try to read the word as a whole word or, if unsuccessful, can try to read the syllables and/or morphemes and make a synthesis. The student thus identifies and gets exposure to the relevant word parts (principle \#3). The aim is not to teach the student to divide words into syllables but to help him identify the relevant word parts. As a last option, he can access TTS. These words are marked with white boxes.

If the student cannot read a red box word independently, he should just have it read aloud (principle \#1). The material does not provide further support for these words. These are either infrequent words or consist of infrequent word parts and/or word parts with irregular neighbors, which are harder to read than words with regular neighbors (Shultz, 2010). This serves to control frustration, an important part of scaffolding; the student is told that it is all right that he cannot read the word. Decoding the word might very well be outside the student's zone of proximal development. Consequently, this feature lessens demands to control vocabulary in instructional texts. Also in this category are a few words in which each letter represents its most common sound. These words are placed in this category because it is assumed that students will use the standard sounds as default when trying to read an unfamiliar word; therefore, no further support is necessary for 
these words. Students should realize that they can sometimes read the red words easily, which could encourage them to try to read these words before activating TTS.

Some words come with an explanation to aid comprehension. Every word in these explanations can be read aloud by TTS.

\section{Research Questions}

The questions that the evaluation of the prototype will shed light on are:

- Do students decode fewer or more words in each category of words independently with or without the scaffold?

- How do individual students use the TTS and sub-word level support functions of the scaffold?

- What do individual students do with and without the scaffold on words that they cannot decode independently?

- How can the eBook prototype or the design for learning be redesigned to make students interact more optimally with the learning material?

\section{Strategy for Data Collection}

Data from the intervention was collected using different methods (Table 1). Screen recordings were the primary source of data, but the teacher and I also kept a shared research log, made observations and exchanged views. I also did a more formal interview with the teacher on two occasions. The various methods make triangulation possible and help contextualize the data from the screen recordings.

Table 1. A chronological overview of the types of data and the purpose of each type of data. Where relevant, the table shows the number of usable recordings.

\begin{tabular}{|c|c|c|c|}
\hline Date & Type of data & Purpose & $\begin{array}{l}\text { \# usable } \\
\text { recordings }\end{array}$ \\
\hline 22.08 .2013 & $\begin{array}{l}\text { Focus group interview with } \\
\text { six teachers. }\end{array}$ & $\begin{array}{l}\text { To get feedback on the prototype and the design } \\
\text { for learning. }\end{array}$ & \\
\hline 18.12 .2013 & $\begin{array}{l}\text { Interview with the teacher } \\
\text { from the intervention class. }\end{array}$ & $\begin{array}{l}\text { To get information about the students, facilities at } \\
\text { the school, her previous teaching methods etc. }\end{array}$ & \\
\hline 29.01 .2014 & $\begin{array}{l}\text { Screen recording with audio } \\
\text { recording of students reading } \\
\text { aloud. }\end{array}$ & $\begin{array}{l}\text { To determine baseline decoding of unfamiliar } \\
\text { text without support. }\end{array}$ & 9 \\
\hline 30.01 .2014 & $\begin{array}{l}\text { Test on single word decod- } \\
\text { ing (OS64). }\end{array}$ & $\begin{array}{l}\text { To determine baseline decoding skills on single } \\
\text { word level. }\end{array}$ & 16 \\
\hline $\begin{array}{l}31.01 .2014- \\
\text { end of inter- } \\
\text { vention }\end{array}$ & $\begin{array}{l}\text { Shared research log with the } \\
\text { teacher. }\end{array}$ & $\begin{array}{l}\text { To share observations of students with the } \\
\text { teacher. }\end{array}$ & \\
\hline $\begin{array}{l}31.01 .2014- \\
07.02 .2014\end{array}$ & $\begin{array}{l}\text { Screen recording of students } \\
\text { interacting with eBook pro- } \\
\text { totype. }\end{array}$ & To study students' interaction with the prototype. & 23 \\
\hline 06.03 .2014 & $\begin{array}{l}\text { Interview with the teacher } \\
\text { from the intervention class. }\end{array}$ & $\begin{array}{l}\text { To catch up on the teacher's experience with } \\
\text { using the learning material with her students and } \\
\text { share views on how to improve the design. }\end{array}$ & \\
\hline 21.03 .2014 & $\begin{array}{l}\text { Screen recording of students } \\
\text { interacting with changed } \\
\text { eBook prototype. }\end{array}$ & $\begin{array}{l}\text { To study students' interaction with the changed } \\
\text { prototype. }\end{array}$ & 5 \\
\hline
\end{tabular}


Screen recording software (Screencast-O-Matic) allowed me to record a visual representation of the students' interaction with the learning material. The students' verbal output was recorded as audio using the built-in microphones of the laptops. The students were instructed to read aloud. This method for structured observation allows for the fairly unobtrusive collection of data and subsequently reliable coding of the data (Bryman, 2012).

\section{The Intervention}

I evaluated the prototype to gain as much knowledge as possible about how different students interact with the learning material to determine why they behaved as they did and to try to make improvements either to the eBook or to the design for learning that guided student interaction with the learning material. The core of the design was the eBook material. If this core did not seem to work for most students under any relevant circumstances, for example designs for learning, the design would have to be abandoned.

The iterative cycles in DBR make it difficult to differentiate between intervention and results. The results from one iteration led to a redesign and thus a more or less different intervention that produced new results. In the present article, I choose to single out the parts of the intervention that are most important for evaluating for whom and under which circumstances the part of the programme theory that concerns scaffolding decoding seems to work.

After collaborating with a group of teachers and thus making significant changes to the eBook features, I evaluated the material with one second-grade class consisting of 19 students (11 boys and 8 girls), but only 14 students participated in the study. Three of the 19 students (or their parents) did not allow me to record them reading. Two students were absent during important parts of the intervention, for example, the introduction of the scaffolding functions, therefore the first recordings of these students are quite uninteresting. These students were not included in the study. One student (student \#1) is bilingual and was often absent due to remedial education. Another student (\#3) often had a support teacher by her side; this student often chose not to participate in the class activities (both normal and intervention activities), and her teachers have sought counselling to take measures to include her. The latter two students were included in the study.

The intervention lasted 11 weeks, but the class engaged in other activities during that period. Sometimes, for example, I had to pause the intervention to make changes to the learning material. I did not, however, have the time or the programming skills to implement all the changes that my observations led me to believe would be improvements to the learning material.

The first three weeks were used to prepare the students to be able to use the scaffold as intended. The first two weeks the students practiced using 86 of the most frequent (and most of them highly irregular) Danish words (the words in the green category in the learning material). This was done to make sure that all students felt that they had seen these words before; in the learning material, the support for these words is limited. In the third week of the intervention, the students familiarized themselves with the app AppWriter Cloud (LingApps), which provided TTS support in the learning material.

To establish each student's decoding skills prior to the intervention, the class did a standardized single-word reading test, OS64 (Nielsen, Kreiner, Poulsen, \& Søegård, 1989) that indicated decoding speed and accuracy. The results are shown in Table 2. 
Table 2. The table shows students' results for the decoding test.

The students are ranked, beginning with the poorest decoder.

\begin{tabular}{|l|c|c|c|c|c|c|c|c|}
\hline $\begin{array}{c}\text { Student } \\
\#\end{array}$ & $\begin{array}{c}\text { Time } \\
\text { spent }\end{array}$ & $\begin{array}{c}\text { Average } \\
\text { time per } \\
\text { task }\end{array}$ & Errors & Skipped & $\begin{array}{c}\text { Over- } \\
\text { looked }\end{array}$ & Passed & Correct & $\begin{array}{c}\text { Percent } \\
\text { correct of } \\
\text { passed }\end{array}$ \\
\hline 1. & $10: 00$ & 13.3 & 18 & 0 & 19 & 45 & 27 & $60 \%$ \\
\hline 2. & $10: 00$ & 16.7 & 1 & 0 & 28 & 36 & 35 & $97 \%$ \\
\hline 3. & $9: 26$ & 8.8 & 17 & 0 & 0 & 64 & 47 & $73 \%$ \\
\hline 4. & $7: 49$ & 7.3 & 0 & 0 & 0 & 64 & 64 & $100 \%$ \\
\hline 5. & $5: 46$ & 5.4 & 0 & 0 & 0 & 64 & 64 & $100 \%$ \\
\hline 6. & $4: 08$ & 3.9 & 0 & 0 & 0 & 64 & 64 & $100 \%$ \\
\hline 7. & $4: 03$ & 4.1 & 0 & 4 & 0 & 60 & 60 & $100 \%$ \\
\hline 8. & $3: 15$ & 3.0 & 0 & 0 & 0 & 64 & 64 & $100 \%$ \\
\hline 9. & $3: 11$ & 3.0 & 1 & 0 & 0 & 64 & 63 & $98 \%$ \\
\hline 10. & $2: 55$ & 2.7 & 0 & 0 & 0 & 64 & 64 & $100 \%$ \\
\hline 11. & $2: 49$ & 2.6 & 0 & 0 & 0 & 64 & 64 & $100 \%$ \\
\hline 12. & $2: 30$ & 2.7 & 0 & 8 & 0 & 56 & 56 & $100 \%$ \\
\hline 13. & $2: 07$ & 2.0 & 0 & 0 & 0 & 64 & 64 & $100 \%$ \\
\hline 14. & $1: 53$ & 2.0 & 0 & 0 & 8 & 56 & 56 & $100 \%$ \\
\hline
\end{tabular}

Furthermore, the students were recorded reading an unknown text on the computer without scaffolding (Table 1, 4th row). This was done to be able to compare student behavior with and without the scaffold.

The students were instructed how to use the scaffold. They were told to try to decode every word without using support. Then, if they were not successful or if they wanted to check that they identified the correct word, they had to look below the word. On several occasions, the students were instructed about what the different colors mean and what they must do to read the different types of words.

The design for learning for how to use the learning material was changed a few times during the intervention. From the outset of the intervention, every student in the class read the same text once individually. The eBooks were digitized picture books that were not adapted linguistically; thus, the narrative could be assumed to be interesting for children, but there was no controlled vocabulary or any other sort of formal adaptation. In the Danish national curriculum, students should read texts at LIX-level 10-15 at the end of grade 2; the texts used in the intervention were LIX 19-23. Before reading in each lesson, the class engaged in a discussion of a theme in the text and a few concepts that were important for understanding the text. This was done to make the students able to understand and be interested in the narrative. The more challenged readers needed more time for reading. After finishing reading, the students were requested to write an answer to a question about the narrative, which only the fastest readers were able to do. 
After several days, I made screen recordings of the students' interactions with the eBook prototype, assuming that the students who had been present for the introduction would have familiarized themselves with the scaffolding functions.

Over the next few weeks, I analyzed the data to see for whom the eBook features seemed to work, what challenges there were and, if possible, to find solutions. The results of this analysis led me to make a significant change in the design of the learning material that was intended to improve the scaffolding of decoding for the poorest decoders. Towards the end of the period, I was working on another redesign that was hoped to make the last two students' interaction with the learning material more beneficial. However, I simply was not able to do the necessary programming and therefore could not evaluate the iteration in this intervention. Both changes will be described later in the article.

\section{Strategy for Data Analysis}

When analyzing the recordings, I used fixed categories that were generated from the programme theory. For each recording, I scored how many of the different categories of words (green, yellow, white, red, and blue) in the texts the students read independently, erroneously, using the support or skipped. This approach allowed me to compare the overall behavior of a student under different conditions (for example, reading without the scaffold and reading with different versions of the eBook).

I was looking for signs that each student was behaving more or less in line with the programme theory; I was not trying to measure an effect on decoding skills, but I did assume that the design of the eBook and/or design for learning had an impact on student behavior. I will express some of these patterns in numbers to show the behavioral pattern of each student, being aware that these numbers have no claim to external validity.

The volume of data collected on each student was uneven. Some students I recorded only once or twice and others I recorded up to five times. In describing the results of the intervention, I will first draw some general conclusions for the group of students in the intervention, but the iterative process of identifying challenges and solutions to the design often involved only one or a few students. Therefore, I pursued observing particular students to see the result of particular iterations. Using realistic evaluation, my aim was not to determine an overall effect, how the whole class was performing, or an overall change in behavior caused by the intervention. Instead, I used the data to identify challenges to the underlying programme theory, focusing on single students as cases. I chose to record and analyze the ones that were most significant and interesting for the ongoing design of the eBook prototype and design for learning. Students who did not really need the support from the scaffold because their decoding skills were adequate for reading the texts I left out after the first recordings.

I stopped recording a student once I had seen he could and did use the scaffold in a beneficial way. In other words, my analysis does not say anything about the consistency in student performance. Student \#4 was an exception; I recorded her three times reading with roughly the same setup to see how her behavior developed over a period of several weeks. This line of inquiry did not yield interesting results, but for this student I have chosen to report average values of the three recordings.

I made 43 recordings, but I did not use all the recordings for analysis. Because I had the students reading unsupervised as much as possible, many things went wrong with the recordings. For example, some students did not turn on TTS or read the text from the previous day. Some recordings are not very interesting because students were distracted, did not read aloud or experienced technical difficulties. On two occasions, I tried to record all the students at once-for the test before introducing the eBook features and once when they had used it for a few lessons. This 
created a lot of disturbance, and some of the recordings failed. For example, only nine of the recordings of students reading the unscaffolded text are usable. The rest of the recordings were made on different occasions. The results of the analysis of the two batches of recordings are reported in the following section.

\section{Results}

\section{Students' Ability to Use the Scaffold}

By analyzing the recordings of some of the students and comparing the results to the test without the scaffold, I concluded that the students all knew how to use the scaffold after using it for reading texts 2-3 times. 4 students underused the scaffold, but they were all able to tell what they were supposed to do to use the scaffold, when asked. However, it was obvious that some of the students needed support in self-regulating their reading.

\section{Independently Read Words}

The data backed up the assumption that students are more likely to be able to read the most frequent words (the green category) and the words with frequent rimes (the yellow category) independently. Figure 4 shows that the best decoders in the class (students \# 6-14) read these words independently when using the scaffold. The observations also show that they read them immediately and effortlessly. In other words, these students did not need TTS for any of these words. In addition, these students could decode no less than $80 \%$ of the red and white words, but very few could decode them all. For most of these students, the overall percentage of words decoded independently would traditionally indicate that the text is suitable for independent reading without the scaffold (Stange, 2013).

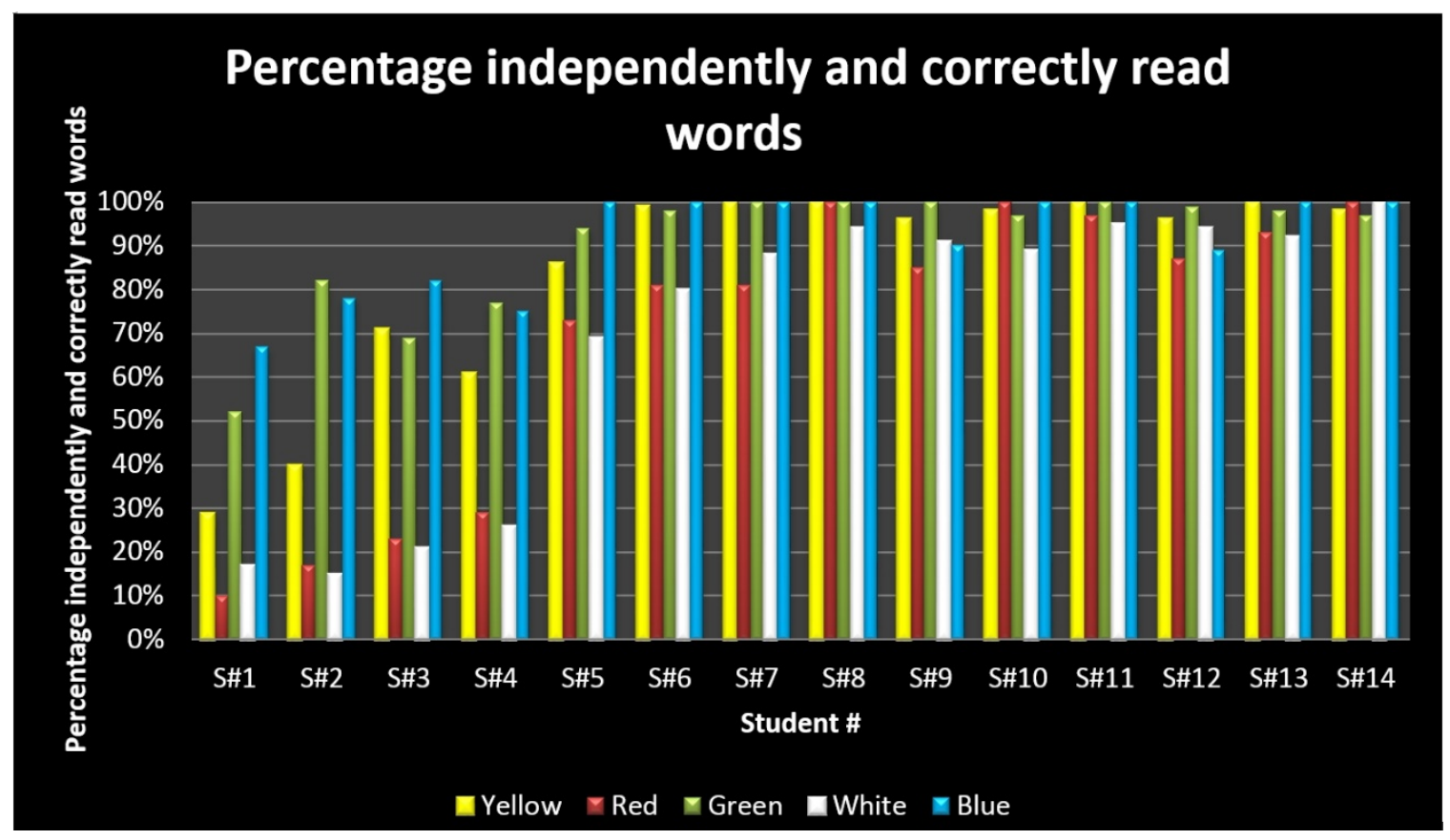

Figure 4. Percentage of the different categories of words read independently by students.

This is an important observation because it shows that for these students it makes sense to limit the TTS support for these words to prevent the overuse of the scaffold without interrupting the 
flow in their reading process. The data also indicate that for these students the prototype was successful in preventing the overuse of TTS.

For the red and white words, the percentage of independently read words was roughly the same for individual students. For the poorer decoders in the class (\# 1-5), there was a significant gap between the green and yellow words read independently on the one hand and the red and white words on the other. There was a significant correlation between decoding skills and the proportion of yellow and green words read independently compared to the red and white words. This result might be caused both by the frequency effect and by the scaffold that led the students to attempt independent decoding of these words. However, what is important is how many of the words the students succeed in decoding independently, with support or erroneously. Rime words posed more difficulty for the poorest decoders in the class than did the green words; practicing the most frequently used words (green words) prior to the intervention might have contributed to this result.

\section{Students' Use of the Support}

Student level of decoding skills was an important contextual variation in the intervention. The functions that the scaffold could and did fulfill for the individual student varied with the level of decoding skills. For the best decoders in the class, limiting access to TTS for the words they were able read to successfully independently prevented the overuse of the scaffold. These students decoded independently if they were able and were offered a target on the few words that they could almost decode or words that consist of infrequent or irregular parts.

Some of the best decoders in the class used the scaffold optimally. For example, student \#11 read well without the scaffold (Figure 5). She had a few errors on white and red words (23\% and $14 \%$ respectively); when she misread a word, she immediately moved on to the next word without reacting to the failed attempt.

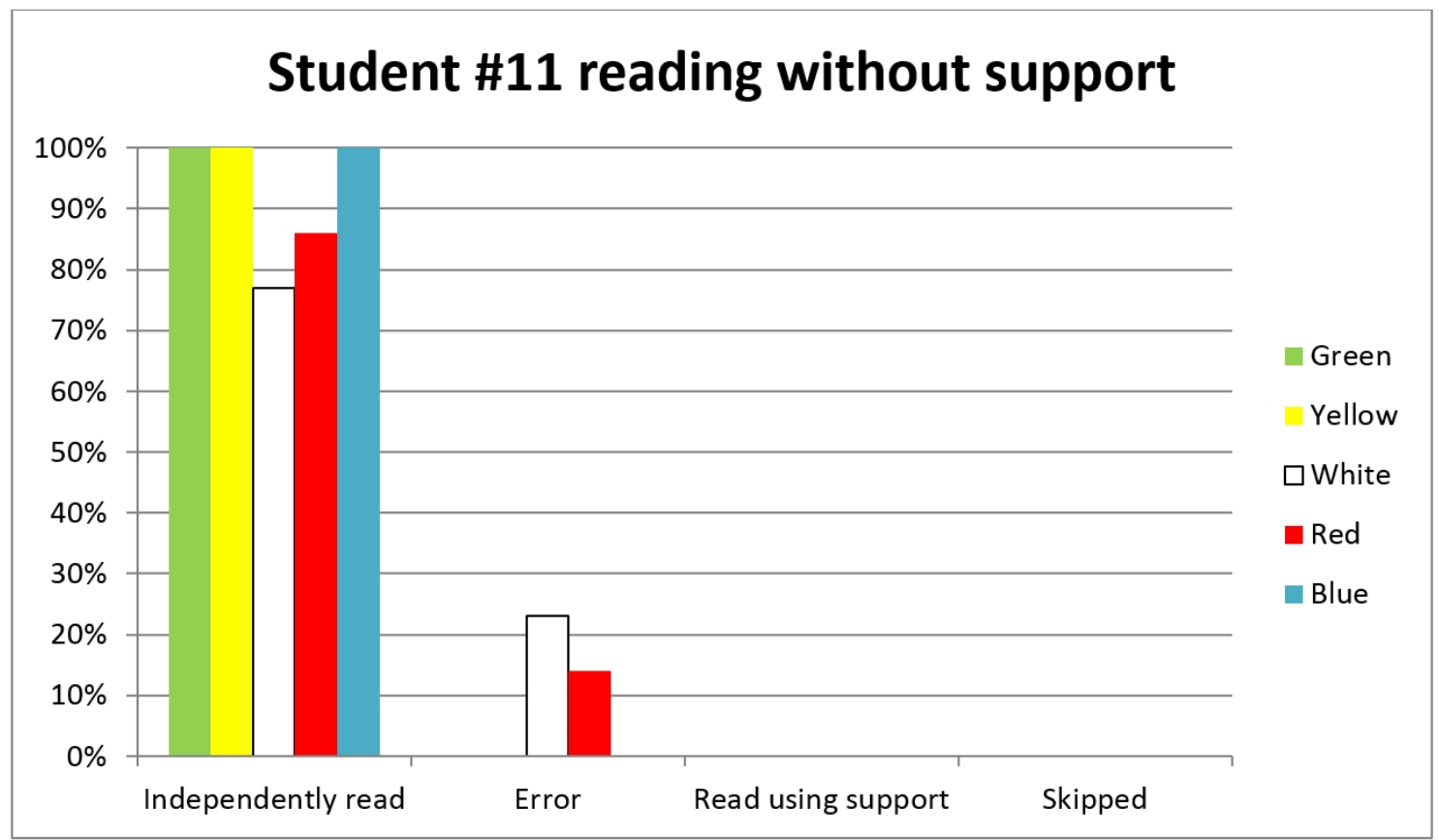

Figure 5. One of the best decoders reading without the scaffold. 
When using the scaffold (Figure 6), she used TTS for all the words she could not decode independently whereby she had a better chance of making meaning of the text and getting a target on the attempted word, thus learning more from the attempt. Student \#7 used the support similarly.

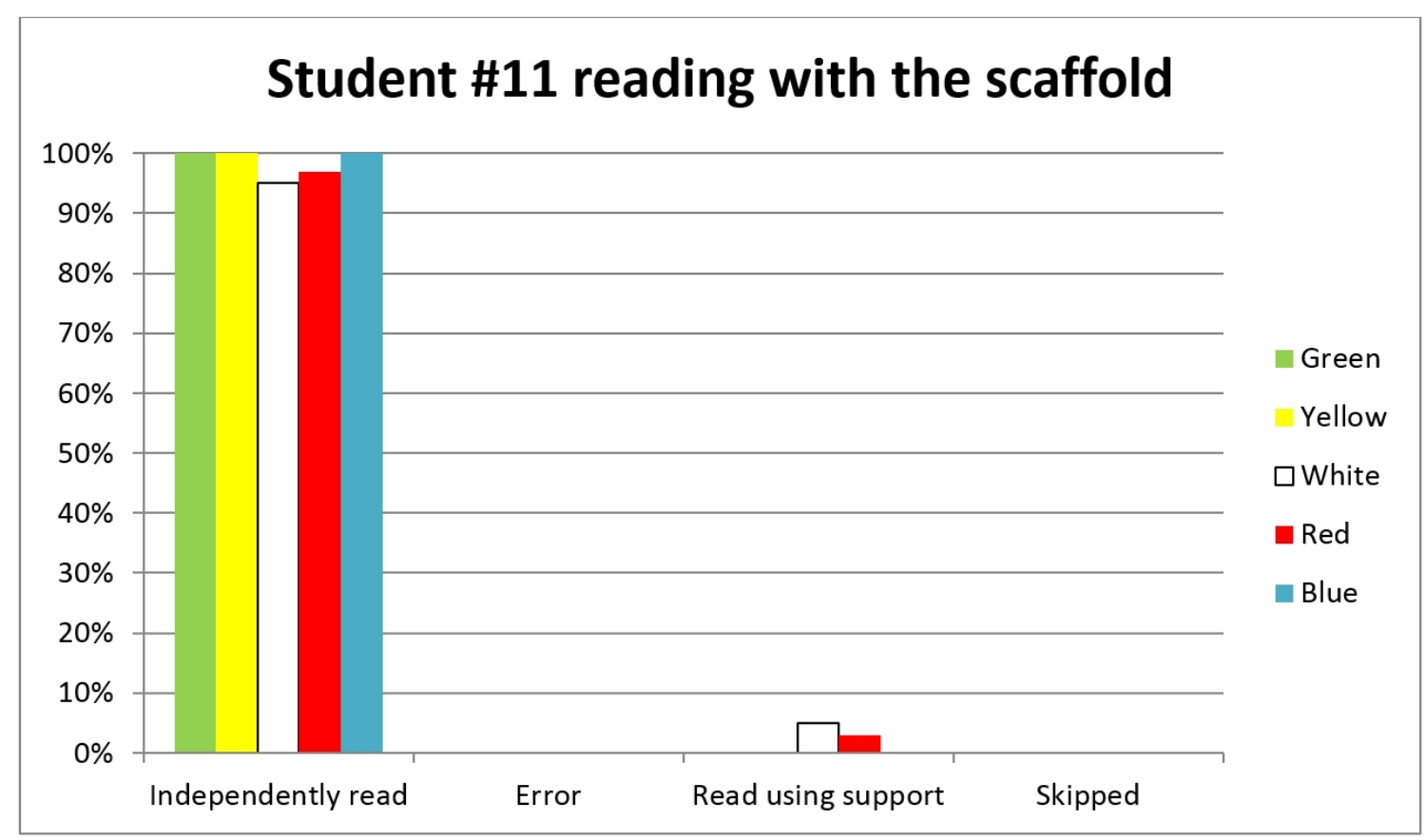

Figure 6. One of the best decoders reading with the scaffold.

Students \#14 and 8 did not use the scaffold but did not need it as they decode every (or almost every) word independently and quite effortlessly. Students \#13, 10, 9, and 6 used the support to some degree but still made some errors. This underuse is not necessarily a problem. For example, student \#9 underused the TTS support, but his hesitation to activate TTS made him succeed in decoding some words independently after a few attempts. Student \#12 underused the support; she moved on when misreading a word without activating TTS. She had very few errors but rushed through the text and was clearly not reading for meaning.

For the more skilled decoders, there is a potential benefit in the class reading the same text, allowing for comprehension work. For most of the students, the texts were challenging to some degree in terms of both decoding and comprehension. Based on the prosody, the students in this study rarely read for meaning but focused instead on decoding the text quickly. For these readers, I calculate with a long term feedback effect from the comprehension work that the class and the teacher will be able to do with the texts when using the eBook. When the students realize that it actually matters for their level of comprehension whether they identify the right words or not, they might self-monitor their comprehension more closely. Rereading the text and/or a variant of paired reading should also move these students towards fluency (Rasinski \& Samuels, 2011).

The poorest decoders (\#1-5) used the scaffold quite differently from the more skilled decoders. These students used TTS very frequently for the red and white words. The scaffold allowed the student to try to read hard words (and for some of the multisyllabic words it offered support in decoding the words) and eventually to access the pronunciation of the words even though they might be outside the zone of proximal development for the student. Figure 4 shows that the poorest readers read significantly more green and yellow words independently, which might be a result of the scaffold directing them towards learning to decode the most frequent words and word parts because TTS was made more indirectly accessible for these words. 
Some of the poorest decoders used the first version of the eBook quite optimally (students \#2 and 4). For one student (\# 5), I succeeded in making changes to the eBook and design for learning that made the student interact more optimally with the scaffold. But for one student (\#1), I was not able to implement the changes I believed necessary due to my lack of programming skills, and for one student (\#3) I did not find a solution.

\section{Student \#2}

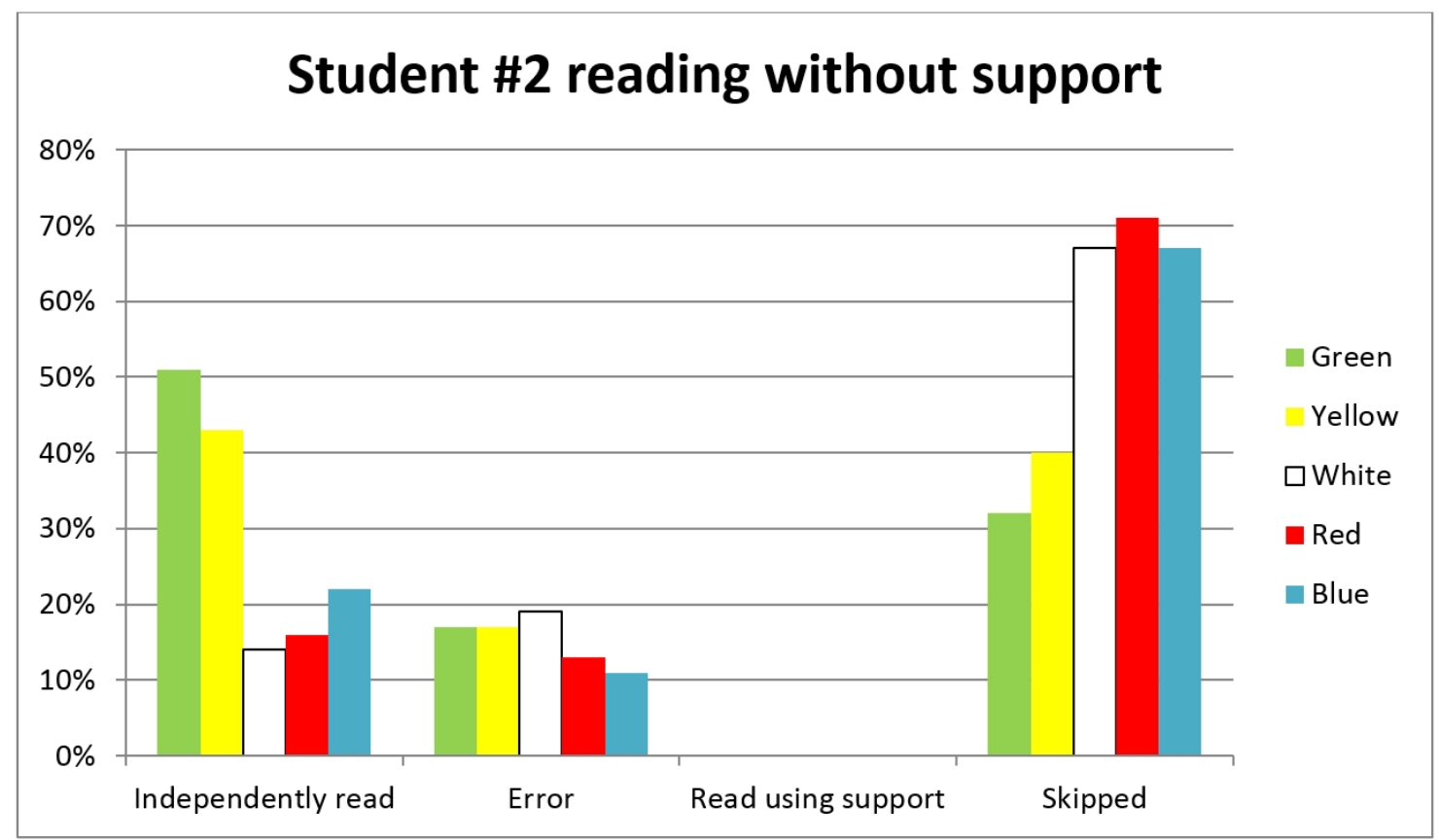

Figure 7. One of the poorest decoders reading without the scaffold.

Student \#2 is bilingual and his test performance indicated that he was a slow decoder, but in the test, he eventually decoded most words correctly. When reading without the scaffold (Figure 7), he was very persistent from the outset. When he encountered a word he could not immediately decode, he kept on trying to decode it. Often he did not succeed and had to skip the word. Eventually, he started skipping words he could not decode immediately rather quickly, and as he moved along he started skipping long words immediately (usually white words) and scanned the text for sight words (mainly green words) and short words.

This student was frustrated by the task of reading a text with words he could not decode and he resorted to sub-optimal strategies for reading. The student gradually performed further and further below his level of decoding skills. Words that he was able to read in the beginning of the text he failed to decode on later occurrences. The student gradually skipped an increasing proportion of the red and white words. However, he managed to decode a greater proportion of green and yellow words independently throughout the text. The student encountered the word "sagde" (Danish for "said"), a very frequent word that has a very consistent rime in it, six times but he misread it or skipped it on all occurrences. Thus, the student had difficulties learning to read new words in this activity. The student skipped roughly as many blue words as red or white words, which indicates that repeats of words did not help him much.

The student lost confidence that he could manage the task. Moreover, according to connectionist theory, he missed the opportunity to both practice decoding many of the words he was able to decode independently and to learn new mappings between orthography and phonology because he never got a target on failed attempts. 


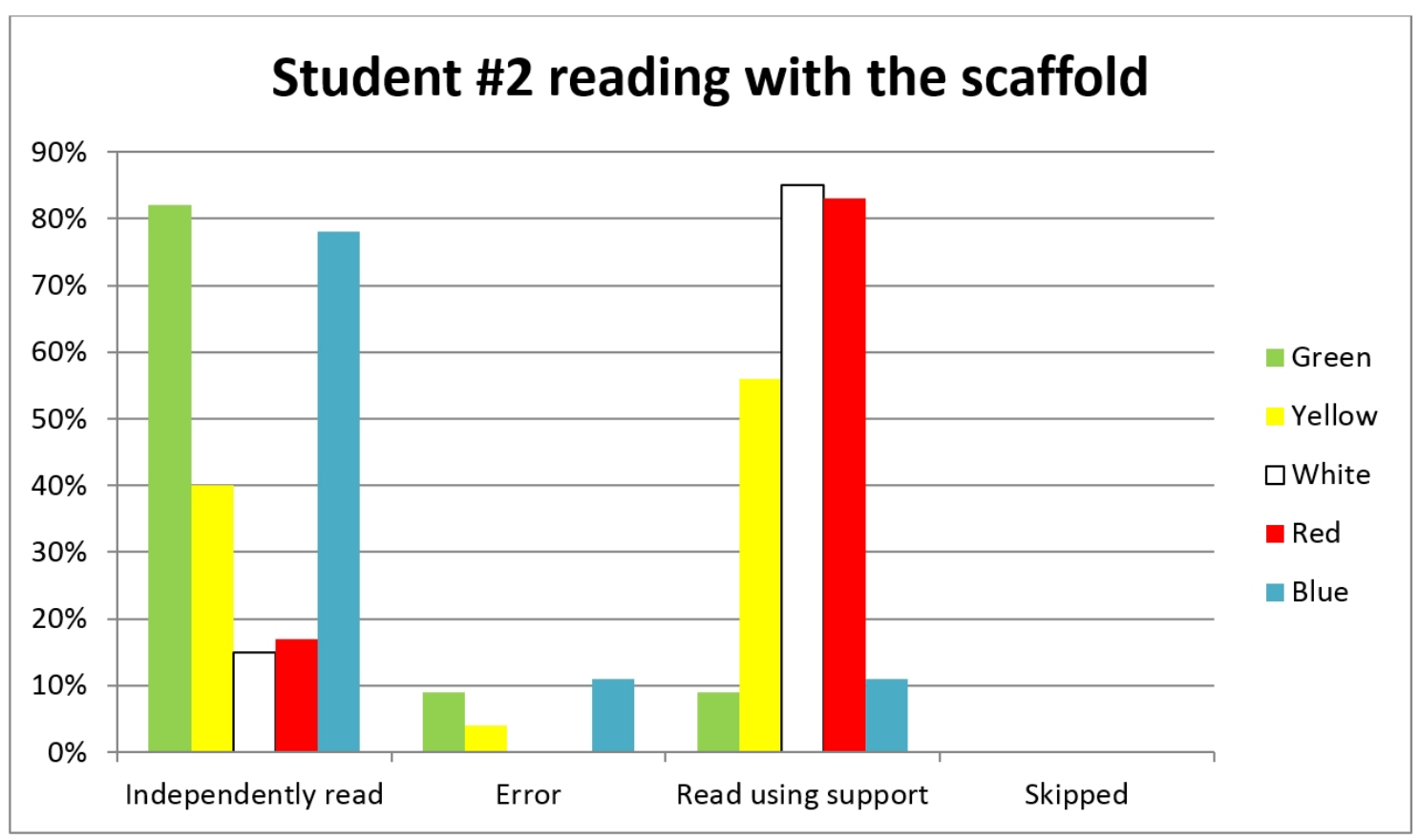

Figure 8. One of the poorest decoders reading with the scaffold.

Without the scaffold, the student skipped about half of all the words in the text, but with the scaffold (Figure 8) the student did not skip any words. The total percentage of independently read words increased by $17 \%$ when he read with the scaffold. In particular, he read more green words independently, probably because the scaffold led him to attempt decoding and pointing the words out as being known to him and because the support was not as directly accessible as with white and red words. The student also had fewer errors; he had no errors for the white and red words. Most of his errors were in the green category, for which he was encouraged not to use support. The student read about the same percentage of yellow words independently with and without the scaffold. However, with the scaffold he used support on most of the words he could not read independently, leaving very few errors. Without the support, these words were skipped or the student made errors. This change should significantly increase the student's advantage of being exposed to the rime and target words. Even though the student overused the support for the yellow words because he got support for a few words that he was able to decode independently elsewhere, the exposure should improve his chances of success with future exposures to the rime. The student independently read roughly the same percentage of the red and white words with and without the scaffold. Therefore, using the scaffold did not make him stop attempting to decode these words independently; but unlike the situation without the scaffold, the student got a mapping from orthography to phonology for the red and white words and maybe additional exposure to the syllables in the white words. For this student, repeats of words became an advantage with the scaffold; in contrast to the situation when reading without the scaffold, the student's awareness that he had just read the word made him read most of them independently. In some instances, the student had used support for the word on the first occurrence, but he read the blue colored repeated words independently and effortlessly. There were instances, apart from the blue words, where the student used support on earlier occurrences and later managed to read the same word independently, but there were also instances of the opposite. Based on these data, it is simply not possible to conclude that the student got new, lasting orthographic representations for any words. 


\section{Student \#4}

Student \#4 just returned to participating in the regular class activities after attending remedial education to improve her reading skills. The teacher had had problems motivating the student to participate in the class activities. However, according to the teacher, using the eBook had a very positive impact on this student's performance and motivation.

This student acted much like student \#2. She was persistent and thorough in the process of decoding the text, skipping very few words when reading with the scaffold. In three recordings of her reading with the scaffold, she behaved similarly. She could decode up to $4 / 5$ of the green words but rarely used support for these words, and she decoded roughly the same percentage independently with and without the scaffold. For the yellow words, the student overused the support, which in the short run is not a problem. With the red and white words, there was a significant difference between reading with and without the scaffold. The student actually decoded more white words independently with the scaffold; she made fewer errors and skipped none of the white words. This means that she attempted decoding on every word and got a target on the words she could not decode independently. Regarding the red words, she decoded the same percentage independently, had fewer errors and got a target on the words she did not manage to decode independently.

\section{Redesigning the eBook}

\section{Challenges to the Design}

Even though the focus of the intervention was supporting decoding, student comprehension or the lack thereof has an impact on decoding. I previously described how the best decoders read with great haste and that their prosody did not indicate comprehension. This means that some of them did not react to errors. For students \# 2 and 4, on the other hand, the task of decoding the text drained cognitive capacity, leaving no chance of comprehending the text. In other words, the best decoders needed to be committed to comprehending the text and the poorest decoders needed a chance to reread the decoded text and to bring the meaning of the words and sentences together in a coherent message.

Student \#5 used the first version of the eBook in a way that indicated that without comprehension and a commitment to making sense of the text, decoding suffered. The student is bilingual and was absent for most of the introduction. He did not use TTS at all. If he did not identify the correct word instantly, he came up with a pronunciation that often did not represent a word and moved on. This student misread some of the green (6\%) and yellow (15\%) words, most of which were read instantly and correctly elsewhere in the recording. As with the other students, the percentage of correctly read words dropped sharply for white (69\%) and red words (73\%).

\section{Redesigning the eBook}

An iteration was devised to meet these challenges. I decided that when the students had read a page with support, the support would be removed so that the text would appear without the scaffold on the following page. In other words, the scaffold was faded (Pea, 2004). The students would then have to check if they had learned to decode the words from interacting with the scaffold. The rereading should allow the students to read more fluently, thus making comprehension more likely (Rasinski \& Samuels, 2011). The students were instructed to continue with the following page when they felt that they read the text fluently. This was a way to hold some of the students accountable and at the same time a means to let the poorer readers experience mastery and see that they were benefiting from using the scaffold. The students were able to go back to 
the scaffolded page to get support (which should control frustration), but it was important to commit the best decoders to being able to read the whole page before moving on.

The teacher preferred that I did not record the students working for a while because it caused a lot of unrest in the class. This meant that I was able to record only once when the students had used this altered scaffold for a while. The recordings show the students reading a very difficult children's book, Byen hvor husene bytter plads (The Town where the Houses Switch Place), a book with lots of vacancies, infrequent words and long, complicated sentences (LIX 25). This text was chosen to see to what extent text difficulty could be offset by the scaffold. Soon, the teacher and I decided that the activity was too difficult for the poorest decoders. We therefore told the students that they should stop reading it and that they would have the rest of the story read aloud. However, the poorest decoders insisted on continuing reading with the scaffold. In the recordings, the students read the text aloud after having practiced with the scaffold. In the process, they independently decided when they were able to move on. Some of them moved very slowly according to the teacher, but we do not know how much time each student spent on each page. I chose to record the poorest decoders reading because I expected a more thorough change in their decoding behavior when working with the new feature.

\section{Results of the Redesign}

For student \#5, committing the student to checking that he was able to read the text independently without the scaffold seemed to have a very positive impact on his behavior. The student must have used the support in the process of learning to read the text. However, in the recording he did not use the support, probably because he wanted to show what he was now capable of. He read all the green words and all the yellow words fluently. He read $93 \%$ of the red words and $85 \%$ of the white words correctly. Supervision and making the student check the results of his learning process can be assumed to have greatly enhanced the positive effect of the student's interaction with the eBook.

Likewise, student \#2 now managed to read all the yellow words independently, roughly 9 out of 10 red and white words and all the blue words. He still struggled with a few of the green words. Student \#4 used the new feature in a slightly different way. She had probably read the text before, but in the recording, she first read using the support on the scaffolded page and then reread the text without the scaffold. It is interesting that she only used support for the red and white words. In the first read through, she managed $44 \%$ of the white words and $64 \%$ of the red words independently, but when rereading she managed $80 \%$ of the white words and $78 \%$ of the red words. The rest were errors. However, using the support seemed to help her read independently. Even though she did not use support for the green and yellow words, the percentage of correctly read words went up in the rereading, most noticeably for the yellow words, where she went from $92 \%$ to $100 \%$. She also learned to read the blue words independently between the readings; on the first reading, she had errors and used support, but in the second she managed all the blue words independently. Perhaps with this student the point is not how many words she read without the scaffold but rather that she seemed highly motivated and was able to use the support to learn to decode the words and the text.

\section{Students \#1 and 3}

For student \# 1, the activities in the intervention were too difficult. When reading in the unsupported condition, he gave up after two sentences with the words: 'I am the poorest reader.' He was very preoccupied with reading the same number of pages as his peers. He skipped many words and overused the support. This student read roughly half of the green words independently and a third of the yellow words. He could use the support and actually used it for some of the green words. For the words that could be read aloud, the student activated TTS before even look- 
ing at them. When supervised, the student used the scaffold quite optimally but relapsed into suboptimal behavior when unsupervised.

Clearly, this student was not challenged within his zone of proximal development. The task of decoding the unknown text was too hard. He seemed to be in need of the teacher support that he was getting in remedial education; the scaffold could not fulfil this role.

I considered two options for adapting the task for student \#1. The first option was to lower the difficulty of the text significantly. This would be a pity because the level of difficulty was appropriate for most of the students in the class. The second option was to simplify the task further so that the task of reading text with the scaffold would become manageable for this student as well. I have designed an iteration that allows the poorest decoders to access the storyline by listening to some of the pages being read aloud - thereby scaffolding comprehension — and focusing student attention on decoding only some of the less challenging parts of the text. The student has to look at each word which is highlighted as the text is read aloud; after listening to a couple of pages the student has to identify some of the written words to check if he really was paying attention to the orthographic representation. This means that the poorest decoders can read the same page in three different versions and this will allow these students to independently reach fluency by putting in the necessary effort. However, this iteration remains to be evaluated.

Student \#3 often had a support teacher by her side to keep her focused on the class activities. When the support teacher was not present, the student very often did not participate. Her interaction with the eBook did not change this. When using the eBook, the teacher made her read one page at a time and then had the student read the text aloud to her. The scaffold presupposes that she self-monitors her reading and works independently; therefore, it was not working well for this student. When recording, I was supervising her most of the time because she would work independently for only very short periods. The student decoded roughly 7 out of 10 of the green and yellow words independently and used support for some of the words she could not manage independently. She used the support for a few of the green and yellow words and used support for most of the white and red words. She decoded most blue words independently and went back to seek support for the rest of the blue words. In other words, there was a fit between the student's decoding capability and the reduction in degrees of freedom and the marking of critical features (Wood et al., 1976) in the scaffold. However, the recruitment and direction maintenance (Wood et al., 1976) that was offered by the scaffold was insufficient for this student. The question is whether working with the scaffold was more or less efficient than the alternatives for this student.

\section{Conclusion and Implications}

The first research question was if students decoded fewer or more words in each category with and without the scaffold. The scaffold minimized overuse of TTS. In other words, the scaffolding design seemed successful in postponing student use of TTS and motivating students to attempt independent decoding, which is essential according to connectionism. Some of the better decoders underused the scaffold, which I consider less of a problem, and I expect this underuse to decrease in the longer term as students get used to decoding for meaning. In general, students who needed the scaffold the most were led to attempt independent decoding of the green and yellow words - where the learning material complicated the access to word-pronunciation.

Most of the students could interact with the eBook in ways that my programme theory predicts are beneficial in strengthening their decoding skills. The students could use the scaffold and used it in different ways, which highlights the importance of the second and third research questions in which I look at individual differences in students' use of TTS and the sub-word level support functions of the scaffold - as well as the possible change in behavior from reading with and without the scaffold. Student baseline decoding skills turned out to be a very important contextual 
factor in how the students used the eBook features. Some of the best decoders in the class just used the support to get a target on the most difficult words - which according to connectionist theory increases the efficiency of the activity on word recognition. In addition, for some of the students who needed the support the most (students \# 2 and 4), a positive change in behavior was seen on the most difficult words, because they skipped fewer hard words but kept on trying to decode them independently.

All students who needed it underused the support for the green category of words. I suggest that the reason for this underuse can be found in the design. My aim was to lessen the availability of TTS on the most frequent words. However, making students access the word in another document for TTS made it too burdensome, and thus some students chose to ignore their errors on these words or guessed (for example student \#1). However, for others such as student \#2, this direction maintenance worked; student \#2 generally succeeded in reading the words independently by trying again.

It was not possible to determine whether students used the syllabification of the white words. The teacher said that many students did and the students said so when we conducted an evaluation in the class. However, the students were not instructed to read the syllables aloud and only on very few occasions did the recordings show use of this supportive feature.

To sum up the results of the fourth research question, the learning material was redesigned to fit student needs. However, not all necessary changes were implemented in the prototype. It is obvious that in a future version of the eBook, the support for the green words must be more accessible because students must have access to a target on these important words; but for scaffolding functions, the targets for the green words should still be less accessible than the support for the red and white words.

The intervention took place when the students were about half way through second grade. This meant that many students did not need support for the green and yellow words. It will be interesting to see whether using the eBook from the beginning of second grade or the latter half of first grade can accelerate the development of decoding skills. Is this way of scaffolding decoding efficient compared to alternative ways of teaching and compared to the more direct and more systematic traditional phonics instruction?

As mentioned in the introduction, I see the connectionist theory of reading acquisition as a potential game changer. If students learn to read words by being exposed to print materials and by being supported in mapping between orthography and phonology and if the support provided in my prototype is sufficient for this mechanism to take place, then reading instruction can be transformed (Puentedura, 2006). A scaffold based on a dual-route mechanism (Coltheart, 2005; Seidenberg, 2005) will call for texts that favor regular words (i.e., words that the student can apply taught rules to), and students will have to be thoroughly prepared for less regular words or words that fall outside what has been taught directly by learning these words by rote. However, the dual mechanism-based approach to reading instruction probably does not prepare students well for reading outside school because students are not supported in trying to read unfamiliar and less regular words, that is, learning to read by self-teaching. Differentiation is difficult because every student has to be taught the same.

The scaffolding method presented in this article aims to support students in reading what they cannot read themselves and strengthening their decoding skills most on the most important units. Connectionism allows for a different theory of the task of learning decoding in a deep orthography by explaining how readers handle quasi-regularity. I will argue that the results of the intervention demonstrate that this scaffold is in harmony with students' own patterns of decoding skills. This approach allows students to work with unfamiliar text and thus to strengthen decoding skills within their zone of proximal development. Furthermore, this approach to teaching decod- 
ing using unfamiliar text helps students activate all the relevant processors (i.e., the phonological, orthographic and context processors) to make meaning of text and make the processes interact as skilled readers do according to connectionist models of reading (Adams, 1994). Every encounter with a word happens in a meaningful context while drawing on the student's previous experience and building up relevant experience for future encounters with similar patterns.

The point of the formative evaluation in this study was not to determine the overall effect of the intervention on comprehension and decoding skills but to assess how likely the intervention was to produce the outcome intended for different students, allowing for the testing and refinement of the eBook material and design for learning. Therefore, even though the students might be using the material in ways that seem beneficial in light of the programme theory, it remains to be seen if the activities really are efficient.

Measuring the effect of students using this prototype of the eBook would not make much sense. The usability of the material was low due to my lack of programming skills. Fortunately, I am now working with skilled programmers who are capable of implementing the design as I now envision it in an optimal way. Testing this professionally developed version of the learning material allows for measuring the effect of students using the learning material in a randomized experimental design.

If the eBook material should turn out to have a positive effect on word recognition and reading comprehension compared to the control conditions, then the result will have high ecological validity (Bryman, 2012) from day one if teachers wish to use it for educational purposes.

The results of this study and the forthcoming measure of the effect of using the learning material are just as relevant to English speaking students as Danish because of the similar orthographies. In Danish digital learning materials for all grades and all subjects, TTS is a common feature. It might be relevant to limit and fine-tune this support in other subjects than L1 to strengthen decoding skills for students who continue to need support for the most frequent words and spellings. Future research in these areas is needed.

\section{References}

Adams, M. J. (1990). Beginning to read: Thinking and learning about print. Cambridge, MA: MIT Press.

Adams, M. J. (1994). Modeling the connections between word recognition and reading. In R.B. Ruddell \& N. J. Unrau (Eds.), Theoretical models and processes of reading (5th ed., pp. 1210-1243). Newark, DE: International Reading Association.

Anderson-Inman, L., \& Horney, M. A. (2007). Supported eText: Assistive technology through text transformations. Reading Research Quarterly, 42(1), 153-160.

Anderson-Inman, L., Horney, M. A., Chen, D. T., \& Lewin, L. (1994). Hypertext literacy: Observations from the ElectroText Project. Language Arts, 7(4), 279-287.

Balajthy, E. (2005). Text-to-speech software for helping struggling readers. Reading Online, 8(4), 1-9.

Barab, S., \& Squire, K. (2004). Design-based research: Putting a stake in the ground. The Journal of the Learning Sciences, 13(1), 1-14.

Betts, E. A. (1957). Foundations of reading instruction with emphasis on differentiated guidance. New York, NY: American Book Company.

Bowey, J. A., \& Muller, D. (2005). Phonological recoding and rapid orthographic learning in third-graders' silent reading: A critical test of the self-teaching hypothesis. Journal of Experimental Child Psychology, 92(3), 203-219.

Brown, G. D. A., \& Deavers, R. P. (1999). Units of analysis in non-word reading: Evidence from children and adults. Journal of Experimental Child Psychology, 73, 208-242. 
Brush, T. A., \& Saye, J. W. (2002). A summary of research exploring hard and soft scaffolding for teachers and students using a multimedia supported learning environment. The Journal of Interactive Online Learning, 1(2), 1-12.

Bryman, A. (2012). Social research methods. New York: Oxford University Press.

Chera, P., \& Wood, C. (2003). Animated multimedia 'talking books' can promote phonological awareness in children beginning to read. Learning and Instruction, 13, 33-52.

Cobb, P., \& Gravemeijer, K. (2008). Experimenting to support and understand learning processes. In A. E. Kelly, R. A. Lesh \& J. Y. Baek (Eds.), Handbook of design research methods in education. Routledge.

Cole, A. D. (2006). Scaffolding beginning readers: Micro and macro cues teachers use during student oral reading. Reading Teacher, 59(5), 450-459.

Collins, A., Joseph, D., \& Bielaczyc, K. (2004). Design research: Theoretical and methodological issues. Journal of the Learning Sciences, 13(1), 15-42.

Coltheart, M. (2005). Modeling reading: The dual-route approach. In M. J. Snowling \& C. Hulme (Eds.), The science of reading: A handbook (pp. 6-23). Oxford: Blackwell.

Cunningham, A. E., Perry, K. E., Stanovich, K. E., \& Share, D. L. (2002). Orthographic learning during reading: Examining the role of self-teaching. Journal of Experimental Child Psychology, 82(3), 185199.

Ehri, L. C. (2005). Learning to read words: Theory, findings, and issues. Scientific Studies of Reading, 9(2), $167-188$.

Gissel, S. (2014). Talking books in reading instruction and student behavior. Designs for Learning, 7(1), 76-98.

Gissel, S. (2015). Using learning materials for design-based interventions. Textbooks and Educational Media in a Digital Age: The Thirteenth International Conference on Research on Textbooks and Educational Media 18 - 20 September 2013, Ostrava - Czech Republic, 61-73.

Goodman, Y. M., Watson, D. J., \& Burke, C. L. (2005). Reading miscue inventory: From evaluation to instruction. Katonah, NY: Richard C. Owen.

Gough, P. B. (1981). A comment on Kenneth Goodman. In M. L. Kamil (Ed.), Directions in reading: Research and instruction (pp. 92-95). Washington, DC: National Reading Conference.

Harm, M. W., McCandliss, B., \& Seidenberg, M. (2003). Modelling the successes and failures of interventions for disabled readers. Scientific Studies of Reading, 7(2), 155-182.

Karemaker, A. M., Pitchford, N. J., \& O'Malley, C. (2010a). Enhanced recognition of written words and enjoyment of reading in struggling beginner readers through whole-word multimedia software. Computers \& Education, 54(1), 199-208.

Karemaker, A. M., Pitchford, N. J., \& O’Malley, C. (2010b). Does whole-word multimedia software support literacy acquisition? Reading and Writing, 23(1), 31-51.

LaBerge, D., \& Samuels, S. J. (1974). Towards a theory of automatic information processing in reading. Cognitive Psychology, 6, 293-323.

Lefever-Davis, S., \& Pearman, C. (2005). Early readers and electronic texts: CDROM storybook features that influence reading behaviours. The Reading Teacher, 58(5), 4-10.

Levy, B. A., \& Lysynchuk, L. (1997). Beginning word recognition: Benefits of training by segmentation and whole word methods. Scientific Studies of Reading, 1(4), 359-87.

Lewin, C. (1998). Talking book design: What do practitioners want? Computers \& Education, 30(1-2), 8794.

Lewin, C. (2000). Exploring the effects of talking book software in UK primary classrooms. Journal of Research in Reading, 23(2), 149-157. 
Liberg, C. (1990). Learning to read and write. Uppsala University (PhD thes.). Reports from Uppsala University, Linguistoics (RUUL) 20.

Littleton, K., Wood, C., \& Chera, P. (2006). Interactions with talking books: Phonological awareness affects boys' use of talking books. Journal of Computer Assisted Learning, 22(5), 382-390.

Lumpe, A. T., \& Butler, K. (2002). The information seeking strategies of high school science students. Research in Science Education, 32(4), 549-66.

Lupker, S. J. (2005). Visual word recognition: Theories and findings. In M. J. Snowling \& C. Hulme (Eds.) The science of reading: A handbook (pp. 39-60). Oxford, UK: Blackwell.

Majgaard, G., Misfeldt, M., \& Nielsen, J. (2011). How design-based research and action research contribute to the development of a new design for learning. Designs for Learning, 4(2), 8-27.

McKenna, M. C. (1998). Electronic text and the transformation of beginning reading. In D. Reinking, M. C. McKenna, L. D. Labbo, \& R. D. Kieffer (Eds.), Handbook of literacy and technology: Transformations in a post-typographic world (pp. 45-60). Mahwah, NJ: Lawrence Erlbaum Associates.

McKenna, M. C., Reinking, D., \& Bradley, B. A. (2003). The effects of electronic trade books on the decoding growth of beginning readers. In R. M. Joshi, C. K. Leong, \& B. L. J. Kaczmarek (Eds.), Literacy acquisition: The role of phonology, morphology, and orthography (pp. 193-202). Amsterdam: IOS Press.

McKenney, S., \& Reeves, T. C. (2012). Conducting educational design research. London: Routledge.

National Reading Panel (NRP). (2000). Report of the National Reading Panel: Teaching children to read (reports of the subgroups). Washington, DC: National Institute of Child Health and Human Development. Retrieved October 19, 2015 from http://www.nichd.nih.gov/about/org/der/branches/cdbb/Pages/nationalreadingpanelpubs.aspx

Nielsen, J. C., Kreiner, S., Poulsen, A. \& Søegård, A. (1989). OS64 og OS120 - Ordstillelæsningsprøver [OS64 and OS120 - Silent word reading tests], Hogrefe Psykologisk Forlag, 2. ed.

Nieveen, N., \& Folmer, E. (2013). Formative evaluation in educational design research. In T. Plomp \& N. Nieveen (Eds.), Educational design research (pp. 152-169). Retrieved October 19, 2015 from http://www.slo.nl/downloads/2009/Introduction_20to_20education_20design_20research.pdf

Olofsson, A. (1992). Synthetic speech and computer aided reading for reading disabled children. Reading and Writing: An Interdisciplinary Journal, 4(2), 165-178.

Olson, R. K., \& Wise, B. W. (1992). Reading on the computer with orthographic and speech feedback: An overview of the Colorado remediation project. Reading and Writing: An Interdisciplinary Journal, $4(2), 107-44$.

Parr, M. (2008). More than words: Text-to-speech technology as a matter of self-efficacy, self-advocacy, and choice. Retrieved from http://digitool.library.mcgill.ca/thesisfile18738.pdf

Pawson, R., \& Tilley, N. (1997) Realistic evaluation. London: Sage.

Pawson, R., \& Tilley, N. (2004). Realistic evaluation. Retrieved October 19, 2015 from http://www.communitymatters.com.au/RE chapter.pdf

Pea, R. D. (2004). The social and technological dimensions of scaffolding and related theoretical concepts for learning, education, and human activity. The Journal of the Learning Sciences, 13(3), 423-451.

Puentedura, R. R. (2006). Transformation, technology, and education. Retrieved October 19, 2015 from http://hippasus.com/resources/tte/part1.html

Rasinski, T. V., \& Samuels, S. J. (2011). Reading fluency: What it is and what it is not. In S. J. Samuel \& A. E. Farstrup (Eds.), What research has to say about reading instruction (4th ed.) (pp. 94-114). Newark, DE: The International Reading Association. 
Reitsma, P. (1988). Reading practice for beginners: Effects of guided reading, reading-while-listening, and independent reading with computer-based speech feedback. Reading Research Quarterly, 23(2), 219235.

Seidenberg, M. S. (2005). Connectionist models of word reading. Current Directions in Psychological Science, 14, 238-242.

Seidenberg, M. S. (2007). Connectionist models of reading. In G. Gaskell (Ed.), Oxford handbook of psycholinguistics (pp. 235-250). Oxford: Oxford University Press.

Seidenberg, M. S., \& McClelland, J. L. (1989). A distributed, developmental model of word recognition and naming. Psychological Review, 96, 523-568.

Share, D. (1995). Phonological recoding and self-teaching: Sine qua non of reading acquisition. Cognition, $55,151-218$.

Share, D. (1999). Phonological recoding and orthographic learning: A direct test of the self-teaching hypothesis. Journal of Experimental Child Psychology, 72, 95-129.

Share, D. (2004). Orthographic learning at a glance: On the time course and developmental onset of selfteaching. Journal of Experimental Child Psychology, 87, 267-298.

Sharma, P., \& Hannafin, M. J. (2007). Scaffolding in technology-enhanced learning environments. Interactive Learning Environments, 15(1), 27-46.

Shultz, T. R. (2010). Connectionism and learning. In P. Peterson, E. Baker, \& B. McGaw (Eds.), International encyclopedia of education, 5 (pp. 476-484). Oxford: Elsevier.

Stange, T. V. (2013). Exploring text level difficulty and matching texts for reading achievement. Education Matters, 1(2). Retrieved October 19, 2015 from http://em.synergiesprairies.ca/index.php/em/article/download/41/16

Tracy, D. H., \& Morrow, L. M. (2006). Lenses on reading. An introduction to theories and models. New York: The Guilford Press.

Treiman, R., Mullennix, J., Bijeljac-Babic, R., \& Richmond-Welty, E. D. (1995). The special role of rimes in the description, use, and acquisition of English orthography. Journal of Experimental Psychology: General, 124(2), 107-136.

Van Daal, V. H. P., \& Reitsma, P. (1993). The use of speech feedback by normal and disabled readers in computer-based reading practice. Reading and Writing: An Interdisciplinary Journal, 5, 243-259.

Vygotsky, L. S. (1978). Mind in society: The development of higher psychological process. Cambridge, MA: Harvard University Press.

Wise, B., Olson, R., Anstett, M., Andrews, L., Terjak, M., Schneider, V., \& Kostuch, J. (1989). Implementing a long-term computerized remedial reading program with synthetic speech feedback: Hardware, software, and real-world issues. Behavior Research Methods, Instruments, \& Computers, 21(2), 173180.

Wood, D., Bruner, J. S., \& Ross, G. (1976). The role of tutoring in problem solving. Journal of Child Psychology and Psychiatry, 17, 89-100.

Ziegler, J. C., \& Goswami, U. (2005). Reading acquisition, developmental dyslexia, and skilled reading across languages: A psycholinguistic grain size theory. Psychological Bulletin, 131, 3-29.

Zucker, T. A., Moody, A. K., \& McKenna, M. C. (2009). The effects of electronic books on prekindergarten-to-grade 5 students' literacy and language outcomes: A research synthesis. Journal of Educational Computing Research, 40(1), 47-87. 


\section{Biography}

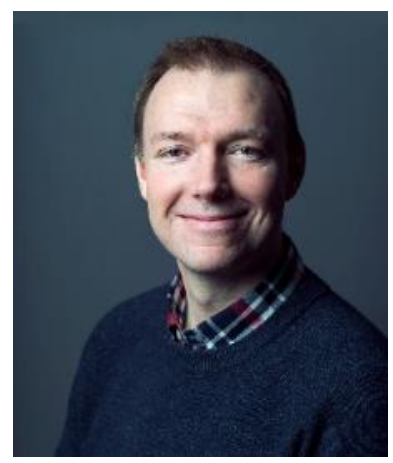

Stig Toke Gissel is currently doing a $\mathrm{PhD}$ developing and testing a digital learning material for reading instruction. He works at The Centre of Applied School Research and in teacher education at University College Lillebaelt, Denmark. His major research interests are Information Technology for educational purposes and digital learning materials, multimodality, and reading instruction. 